\title{
G Research Square \\ A Tripartite Analysis of Online Healthcare Platforms: Evidence from Spring Rain Doctor in China
}

\section{Xia Cao}

Harbin Engineering University

Lanting Zhang ( $\nabla$ zhanglanting913@163.com )

Harbin Engineering University https://orcid.org/0000-0003-3693-203X

Dan Lv

Harbin Engineering University

Weijia Li

Harbin Engineering University

\section{Zeyu Xing}

Harbin Engineering University

\section{Research article}

Keywords: online healthcare platform, evolutionary game theory, tripartite stakeholders

Posted Date: October 14th, 2020

DOI: https://doi.org/10.21203/rs.3.rs-39724/v2

License: (c) (1) This work is licensed under a Creative Commons Attribution 4.0 International License. Read Full License 


\title{
A Tripartite Analysis of Online Healthcare Platforms: Evidence from Spring Rain Doctor in China
}

\author{
Xia Cao, Lanting Zhang*, Dan Lv, Weijia Li and Zeyu Xing
}

Prof. Xia Cao, Email: caoxia@hrbeu.edu.cn

School of Economics and Management, Harbin Engineering University

Dr. Lanting Zhang (Corresponding author), Email: zhanglanting913@163.com

School of Economics and Management, Harbin Engineering University

Dr. Dan Lv, Email: 1ddh283671881@hrbeu.edu.cn

School of Economics and Management, Harbin Engineering University

Dr. Weijia Li, Email: 645292528@qq.com

School of Economics and Management, Harbin Engineering University

Dr. Zeyu Xing, Email: xingzeyusmile@163.com

School of Economics and Management, Harbin Engineering University 


\title{
A Tripartite Analysis of Online Healthcare Platforms:
}

\section{Evidence from Spring Rain Doctor in China}

\author{
Xia Cao ${ }^{1}$, Lanting Zhang ${ }^{1, *}$, Dan $\mathrm{Lv}^{1}$, Weijia $\mathrm{Li}^{1}$ and Zeyu Xing ${ }^{1}$ \\ 1 School of Economics and Management, Harbin Engineering University, Harbin 150001, China. \\ * Correspondence: zhanglanting913@163.com
}

\begin{abstract}
Background: Online healthcare platform (OHP) is a new form of medical treatment, which solves the problems of unbalanced distribution of medical resources and expensive medical treatment in China. Especially under the epidemic of COVID-19, OHP has greatly reduced the medical pressure of the hospital and the risk of cross infection.
\end{abstract}

Methods: This paper uses evolutionary game theory to analyze behavioral strategies and their dynamic evolution in the promotion of OHP, and then numerical simulations are carried out with the help of program compilation.

Results: The results demonstrate that: (1) both the stricter qualification inspection of doctors and the more investment in information protection promote the participation of doctors and the use of patients; (2) with a higher initial probability of doctors joining, the possibility for patients in using OHP and platforms to provide standardized online healthcare services becomes higher; (3) if the initial probability of patients using is higher, the possibility for doctors to join OHP and platforms to provide standardized online healthcare services raises; (4) the trend of doctors joining the platform is affected by factors, such as registration cost, time cost, reputation loss; (5) the tendency of patients in using online healthcare is mainly decided by the cost.

Conclusions: Based on theoretical analysis, this article takes the Spring Rain Doctor OHP as an example to verify the game results. Therefore, OHP should attach importance to the inspection of doctors and the protection of privacy information, and strengthen the publicity in remote places. At the same time OHP can promote the active participation of grassroots doctors, and set a reasonable evaluation mechanism, so as to popularize online medical treatment among patients further. 
Keywords: online healthcare platform; evolutionary game theory; tripartite stakeholders

\section{Background}

The OHP can use information technology to express the medical ecosystem in the form of a community network. This medical ecosystem involves doctors, patients and hospitals. OHP provides patients and doctors with a communication platform which is centered on medical information. It also provides medical search and evaluation, registration, health consultation and other services [1]. Unlike traditional medical services, OHP provides a special form of service which allows doctors to directly deliver medical service information to patients with medical needs [2]. In 2020, due to the outbreak of the COVID-19, the public are mostly anxious about going to the hospital, especially for patients with mild cold symptoms. Therefore, the OHP has received unprecedented attention due to its benefits such as convenience, cost, flexibility and time savings $[3,4]$. According to a report by Apple Inc, there are more than 5000 e-health applications worldwide that can provide online health services [5]. OHP (e.g., haodf.com, chunyuyisheng.com, zocdoc.com etc.) are increasingly popular among patients in China and the U.S. [6].

Global online health care originates in the United States. Teladoc is the earliest and largest Internet medical enterprise in the United States which was listed in 2015. Its main business is online consultation service. At present, Teladoc has more than 10,000 corporate customers, including more than 300 Fortune 1000 companies. These large clients brought their total membership to 23.2 million, which brought in revenue of $\$ 197.5$ million. Teladoc data shows that after 15 years of development, it has completed more than 2 million initial consultations, saving users 493 million dollars.

In China, due to the huge population and uneven distribution of medical resources, a large number of hospitals are severely crowded [7]. Due to the increase in medical demand and government policies, OHP is developing rapidly in China [8]. As early as July 2015, the State Council formally issued the "Guiding Opinions on Actively Promoting the “'Internet+' Action", which clearly proposed the promotion of a new model of online health care and the development of Internet-based health care. In 2018, the General Office of the State Council issued the "Guiding Opinions on Promoting the Development of Internet + Medical" to optimize resource allocation and meet the growing medical needs. In 2020, the National Health Commission issued the "Notice of the General Office of the National Health Commission on Doing a Good Job in Internet Diagnosis and Consultation Services in the Prevention and Control of Epidemic Situations", which clearly stated that it is necessary to give full play to the 
advantages of Internet medical services and vigorously develop Internet diagnosis and treatment services, especially Internet consultation service for fever patients. In early 2020, after the outbreak, due to safety considerations, Chinese users have a great demand for online healthcare services. As of February 13, industry leaders Ali Health, Pingan Good Doctor, and Wei Ning Health have increased by 58\%, 34\%, and $48 \%$ since the beginning of the year. During the Spring Festival of 2020, the highest daily activity of independent apps in the online healthcare field reached 6.712 million, with a maximum increase of close to 1.6 million, or an increase of $31.28 \%$. It shows that OHP has great potential for development. For patients, OHP can reduce transaction costs brought by geographical and time constraints, while improving convenience $[9,10]$. OHP can support patient self-health management by promoting the sharing of health-related knowledge with patients [6]. By browsing the doctor's homepage on the platform, patients can view the doctor's information and understand the doctor's training, professionalism and the effectiveness of the treatment [11]. As for doctors, they can improve the utilization of their time by answering patients' questions in their spare time through OHP [7]. Doctors can also actively use OHP to obtain economic and social benefits [12]. At the same time, OHP can promote doctor-patient communication to a certain extent, reduce the pressure of hospital diagnosis and treatment, and resolve medical resource shortages and doctor-patient disputes [13,14]. However, the rapid development of online healthcare has also brought many problems. Series of problems are caused owing to the imperfection of relevant laws and regulations for OHP in China, such as the lack of effective supervision of platform, the uneven quality of online medical platforms, the low barriers to entry and the low degree of specialization [15]. Some platforms have underinvested in information maintenance, leading patients face the risk of leakage of private information [16]. The OHP lacks strict inspection of doctors' qualifications, lacks training for doctors' practice and the quality of doctors' medical services varies, leading to misdiagnosis and reducing patient satisfaction [17]. These problems not only cause hidden dangers to the health and privacy of patients, but also restrict the further development of online healthcare in China. Therefore, it is necessary for us to conduct further research on OHP.

Scholars usually study OHP from the perspectives of patients, doctors and platforms. From the perspective of patients, existing literature mainly focuses on patients' willingness to use and patients' satisfaction with OHP. In terms of the influence factors of willingness to use, scholars founded that perceived value, attitude, perceived behavior control, technology anxiety, and self-actualization need positively affected the behavior intention of older users [18]. The disease risk can moderate the 
relationship between physicians' service quality and patient choice [19]. The performance expectations, social influence and credibility of network health information are also the key factors that affect patients' acceptance and use of OHP [20]. The level of education effects the willingness to use of patients, too [21]. And the response time, the depth of interaction and the service content of the first consultation have a significant impact on the patients' follow-up consultation behavior [6]. Jung and Padman founded that primary physicians are of critical importance in encouraging patients to use virtualized healthcare delivery [22]. In terms of the influence factors of patients' satisfaction with OHP, scholars founded that distributional fairness, procedural fairness and interpersonal fairness in OHP exert significant direct effects on patients' trust, and patients' trust has significant effects on satisfaction [23]. Some scholars also verified that social support, information quality, and service quality exert significant direct effects on perceived usefulness and patient satisfaction [24], and the patient satisfaction with OHP is positively affected by perceived usefulness [25]. At the same time, service prices also affect satisfaction, and they show an inverted U-shaped relationship [9]. In addition, Amin believed that the hospital information system (HIS) can improve the efficiency of doctors, reduce the waiting time of patients, provide patients with convenient services and useful information and improve the patients' satisfaction [26].

Most studies have been conducted from the perspective of patients. While it is imperative to understand how patients benefit from OHP, OHP will be viable only when participating doctors also gain returns from OHP [27]. OHP requires significant engagement from doctors, as they provide doctordriven services [28]. In OHP, doctors provide consultation services, knowledge and information to help patients understand their diseases and obtain treatments [29]. Doctors' contributions, such as providing consultation service and healthcare information, promote the development of such platforms in the long term [30]. Therefore, from the perspective of doctors, some scholars concerned about the influencing factors of doctors joining OHP. Guo studied the impact of status capital and decision capital on the social and economic returns of different doctor groups. The results show that doctor's decision capital is a professional component which is important to platform maintaining exchange returns [27]. Chen combined the expectancy theory and the Bagozzi, Dholakia, and Basuroy (BDB) model, the results show that extrinsic motivations(i.e., extrinsic rewards, expected relationships, and image) and intrinsic motivation (i.e., a sense of self-worth) significantly influence the desire to serve patients well, which in turn positively affects the willingness to offer free services and the willingness to offer paid services [31]. Ma founded that performance expectations, effort expectations, social impact and convenience 
conditions have a positive impact on doctors' willingness to use and the usage behavior [32]. Yang and Zhang thought that doctors would obtain social support from interaction with patients, and those supports could promote doctors' behaviors in OHP [33]. Yang founded that reputation, monetary rewards and doctor-patient interaction positively influence doctors to contribute to OHP, and the doctor's professional status moderates the relationship between motivators and the resulting contribution [30]. Liu put forward that doctors participate in OHP in order to provide healthcare services to patients and become popular among users [34]. Doctors delivers heightened reputation and other returns while improving the provision of healthcare services [35].

From the perspective of platforms, scholars usually study the impact of platforms on society. Liu and Yang founded that OHP can solve the problem of information asymmetry between doctors and patients [36]. Mcgeady studied the information transfer between patients and doctors and founded that the OHP can increase the communication between patients and doctors and improve the quality of care [37]. Goh studied the social value of OHP services. He believed that the OHP can make medical information break through geographical boundaries and pass from the city to the countryside, which greatly improve the rural medical environment and achieved social value [38]. Venkatesh founded that the emergence of Internet medical services could help rural pregnant women obtain online healthcare information. It can alleviate the problem of uneven distribution of medical resources in urban and rural areas and greatly reduce the infant mortality rate [39]. Wu founded that the OHP can use the Internet to promote the flow of high-quality doctor resources and medical information services across regions, which is beneficial to improve the uneven distribution of medical resources in China [40].

To sum up, in existing research, online healthcare research mainly focuses on the willingness and motivation of patients and doctors. Although some scholars study the impact of platforms on society, few studies focus on the influencing factors of platforms' behaviors. This paper makes three different contributions. Firstly, we analyze the influencing factors of platform' behaviors. At the same time, from the perspective of economic benefit and social benefit, this paper analyzes the behaviors of the tripartite stakeholders simultaneously. Secondly, few studies have focused on the dynamic evolution and mutual influence of the behaviors of different subjects in online healthcare. This paper builds an evolutionary game model, analyzes the evolutionary stabilization strategy of online healthcare stakeholders, and uses program compilation for numerical simulation. Thirdly, this paper verifies the simulation results through the case analysis of Spring Rain Doctor platform. We put forward feasible suggestions to the promotion 
of online medical treatment. This work is of great importance to improving the imbalance of medical resources. The research framework of the whole paper is shown in figure 1.

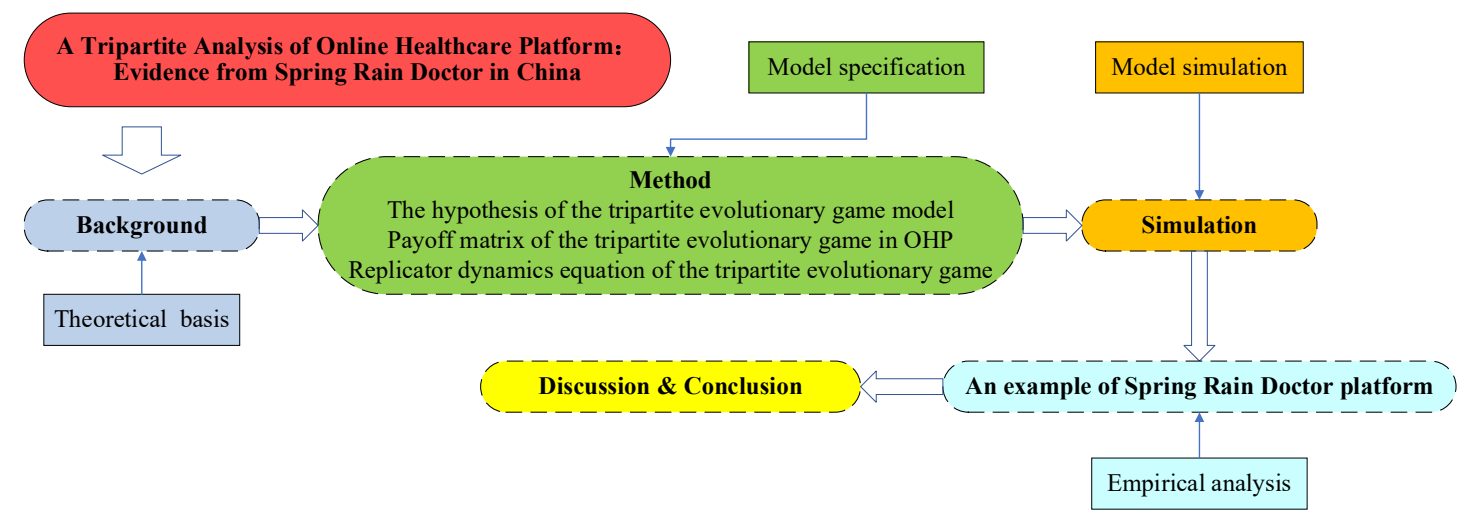

Figure 1. The research framework of the whole paper

\section{Methods}

\section{Evolutionary Game Theory in Healthcare}

Evolutionary game theory is derived from the concept of evolutionary stability strategy [41]. It was originally developed in the economics field to study the social interactions [42]. This method takes the group of participants with limited rationality as the research object, and examines the evolution trend of group behavior from the point of view of system theory. Over the last few decades, the evolutionary game theory has been widely adopted by economists, sociologists, social scientists, as well as the philosophers [43].

The concept of evolutionary game theory also has been used among the access to the healthcare. Chen et al. leveraged the evolutionary game theory to build a novel model to capture the behaviors of hospitals and patients in mHealth, then they analyzed the payoff matrix between hospitals and patients such that a replicator dynamic system can be built [44]. Li et al. proposed a new prediction model of infectious diseases with new vaccination strategies based on network structures and dynamic replicator [45]. Antoci et al. analyzed the relations between defensive medicine, medical malpractice insurance and litigious behaviors, by an evolutionary game between physicians and patients [46]. Mary et al. constructed a theoretical model in which physicians' treatment choices depend on patients' characteristics and on the recent choices of nearby peers-either because there are local knowledge spillovers or because physicians want to conform to local practice patterns [47]. Yu used evolutionary game theory to analyze behavioral strategies and their dynamic evolution in the implementation and 
operation of telemedicine [48]. Through these studies, game theory has the possibility to provide a new theoretical basis for future research on the healthcare.

\section{Evolutionary stable strategy}

Maynard Smith formulated a central concept of evolutionary game theory called the evolutionary stable strategy (ESS) [49]. ESS is the strategy when game players continuously learn and imitate successful strategies in the evolution process and finally reach a stable state after improving their own strategies. The replication dynamic equation is a dynamic differential equation, which is used to express the frequency that a particular strategy is selected by a class of groups. It can be expressed by formula:

$$
\frac{\mathrm{d} x_{i}}{\mathrm{~d} t}=x_{i}\left(u_{s i}-\bar{u}\right)
$$

where $x_{i}$ denotes the frequency of strategy $s_{i}, u_{s i}$ denotes the expected return of strategy $s_{i}$ selected by this group, $\bar{u}$ denotes the average expected return of this group. When interference factors make $x$ smaller than $x^{*}, \mathrm{~d} x / \mathrm{d} t$ needs to be bigger than 0 . And when $x$ is bigger than $x^{*}, \mathrm{~d} x / \mathrm{d} t$ needs to be smaller than 0 , so as to achieve a stable state.

In summary, evolutionary game theory based on the assumption of bounded rationality, considering the interaction between game players. Through multiple games, players constantly learn and improve their strategies, and finally reach an evolutionary stable state.

\section{The Hypothesis of the Tripartite Evolutionary Game Model}

In China, the enterprise-based mode is the main mode of online healthcare, accounting for $70 \%$ of the total. Internet companies build OHP and cooperate with doctors. The platforms need to contact doctors and inspect the qualifications of doctors. During this time, the platforms need to pay more costs. Also, the platform needs to invest in information protection. The higher platforms invest, the higher the risk of cost recovery that platforms confront.

From the perspective of doctors, doctors can obtain economic and social benefits by joining OHP [27]. Specifically, doctors can obtain additional income and build a reputation by providing good online healthcare services [23,31]. In OHP, reputational reward obtained by doctors mainly comes from the patients' feedback such as their ratings and reviews [50]. The reputation reward is especially crucial for doctors to enhance their own career and occupational influence [33,50]. At the same time, doctors need 
to pay the time costs and registration costs. When the platforms do not strictly inspect doctors, doctors will face reputation loss due to misdiagnosis and low patient satisfaction. When the platforms' investment in information protection is insufficient, doctors will face the risk of leakage of private information.

From the patients' perspective, patients can save time and money by using OHP. However, patients may face the risk of being misdiagnosed and divulged of privacy.

The relationship among the three stakeholders is shown in Figure 2.

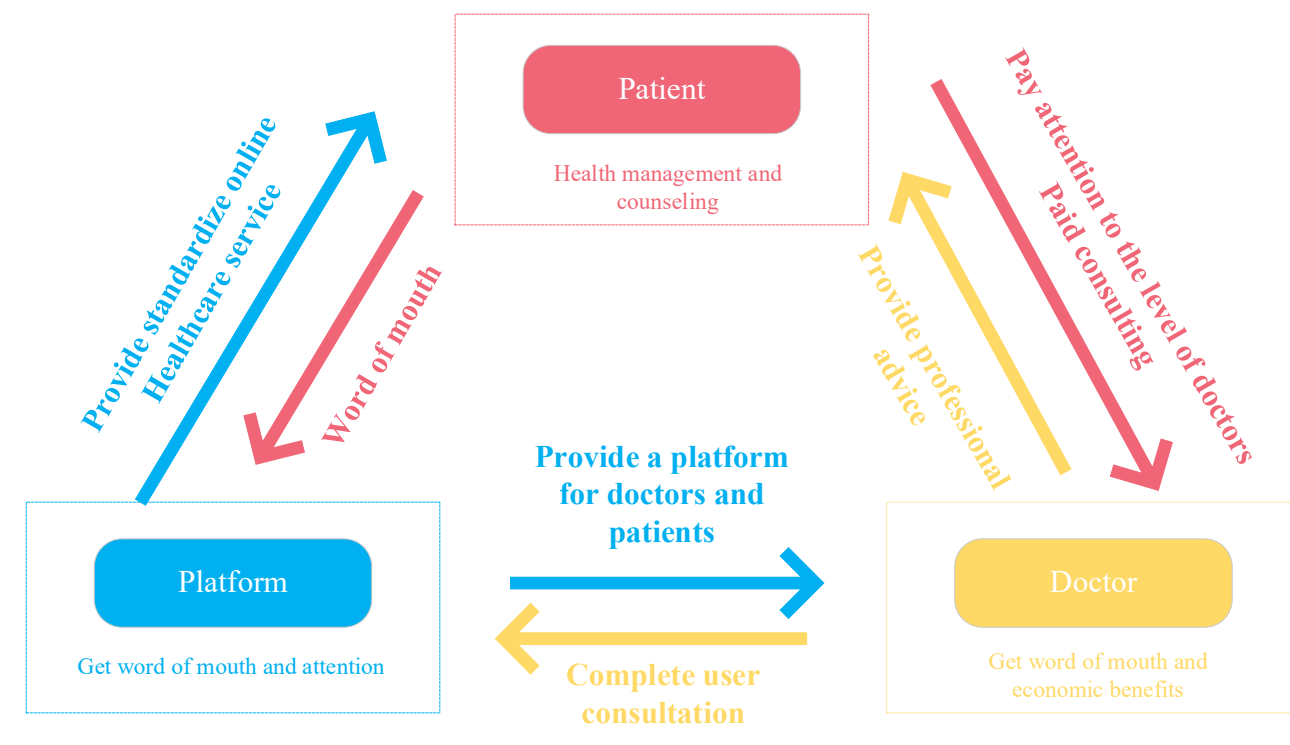

Figure 2. The relationship among the three stakeholders

The following hypotheses were tested in this study:

(1) The promotion of OHP is influenced by three groups: doctors, patients and online healthcare platforms. All the groups with bounded rationality can alter their own strategies by imitating and learning proven behaviors to obtain maximum revenues.

(2) Doctors take two courses of action: One strategy is to join OHP (join), while the other is not to join OHP (not join). Thus, the strategy space of doctors is S1 \{join, not join\}. Patients take two courses of action: One strategy is to use OHP, while the other is not to use OHP. Thus, the strategy space of patients is S2 use, not use\}. Online healthcare platforms take two courses of action: One strategy is to provide standardized online healthcare services, while the other is not to provide standardized online healthcare services. Thus, the strategy space of platforms is S3 \{provide, not provide\}.

(3) The assumptions are that doctors may with $x$ probability adopt the 'join' strategy, and with (1-x) probability adopt the 'not join' strategy. Patients may with $y$ probability adopt the 'use' strategy, and with $(1-y)$ probability adopt the 'not use' strategy. Platforms may with $z$ probability adopt the 
'provide' strategy, and with (1-z) probability adopt the 'not provide' strategy, in which $0<x<1,0$ $<y<1$, and $0<z<1$, respectively.

(4) When the doctors join and the patients use OHP, the doctor's incomes are $r_{1}$, and the costs of the doctor's OHP registration and qualification certification are $c_{1}$. Meanwhile, the doctor's time costs are $c_{2}$. The platforms' qualification inspect strength coefficient (QISC) is $\alpha$ and information protection investment strength coefficient (IPISC) is $\beta$. When the platforms do not provide standardized online healthcare services, the QISC of platforms is less than 1. It may lead to misdiagnosis or low patient satisfaction. The reputation loss suffered by the doctor is $(1-\alpha) c_{3}$. At the same time, the IPISC of platforms is less than 1, and the information leakage loss suffered by doctors is $(1-\beta) c_{4}$.

(5) The health benefit of patients using OHP is $e_{1}$. When patients choose to go to hospital instead of using OHP, the health benefit which they obtain is $e_{2}, e_{1}<e_{2}$. The time and money saved by patients using OHP is $e_{3}$. When doctors join OHP, patients use OHP and platforms provide standard online healthcare services, a solid trust relationship is established between patients, doctors, and platforms. At this time, the patients obtain an additional benefit of $L$. The costs of patients using OHP are $h_{1}$. When doctors join OHP, patients use OHP and the platforms do not provide standardized online healthcare services, the health loss of patients is $(1-\alpha) h_{2}$, and the loss of patients' disease information leakage is $(1-\beta) h_{3}$. Regardless of whether doctors join OHP, when patients use OHP and the platforms do not provide standardized online healthcare services, the loss of the patient's identity information leakage is $(1-\beta) h_{4}$.

(6) When the platforms provide standardized online healthcare services, doctors join OHP and patients use OHP, the economic benefit obtained by the platform is $w_{1}$. At this point, the social reputation incomes that the platforms get are $M$. When the platforms provide standardized online healthcare services, the platforms' qualification inspect coefficient for doctors is 1, and the platforms' information protection investment intensity coefficient is 1 . The costs of platforms inspect doctors' qualification are $t_{1}$, and the costs of platforms' information protection investment are $t_{2}$. When the platforms do not provide standardized online healthcare services, the costs of inspecting doctor qualification are $\alpha t_{1}$, and the costs of information protection investment is $\beta t_{2}, 0<\alpha<1,0<\beta<1$. When the platforms do not provide standardized online healthcare services, the compensation for the patients' health loss is $(1-\alpha) F_{1}$ and the compensation for the patients' disease information leakage is 
$(1-\beta) F_{2}$. The compensation for the patients' identity information leakage is $(1-\beta) F_{3}$. The compensation for the doctors' information leakage is $(1-\beta) G$. When patients use OHP, doctors join OHP and the platforms do not provide standardized online healthcare services, the social reputation loss suffered by the platforms is $N$.

\section{Payoff Matrix of the tripartite Evolutionary Game in OHP}

Based on the above assumptions, a tripartite evolutionary game model including doctors, patients, and platforms under bounded rationality was constructed. The payoff matrix of the three groups is shown in Table 1 and Table 2.

Table 1. Payoff matrix when the platforms provide standardized healthcare services $(z)$

\begin{tabular}{ccc}
\hline & join $(\boldsymbol{x})$ & not join $(\mathbf{1 - x})$ \\
\hline \multirow{3}{*}{ use $(y)$} & $r_{1}-c_{1}-c_{2}$ & 0 \\
& $e_{1}+e_{3}-h_{1}+L$ & $e_{2}$ \\
& $w_{1}-t_{1}-t_{2}+M$ & $-t_{1}-t_{2}$ \\
& $-c_{1}$ & 0 \\
$\operatorname{mot}$ use $(1-y)$ & $e_{2}$ & $e_{2}$ \\
& $-t_{1}-t_{2}$ & $-t_{1}-t_{2}$ \\
\hline
\end{tabular}

Table 2. Payoff matrix when the platforms do not provide standardized healthcare services $(1-z)$

\begin{tabular}{ccc}
\hline & join $(\boldsymbol{x})$ & not join (1-x) \\
\hline \multirow{2}{*}{ use $(y)$} & $r_{1}-c_{1}-c_{2}-(1-\alpha) c_{3}-(1-\beta) c_{4}$ & 0 \\
& $e_{1}+e_{3}-h_{1}-(1-\alpha) h_{2}-(1-\beta)\left(h_{3}+h_{4}\right)$ & $e_{2}-(1-\beta) h_{4}$ \\
& $w_{1}-\alpha t_{1}-\beta t_{2}-(1-\alpha) F_{1}-(1-\beta)\left(F_{2}+F_{3}+G\right)-N$ & $-\alpha t_{1}-\beta t_{2}-(1-\beta) F_{3}$ \\
not use $(1-y)$ & $-c_{1}-(1-\beta) c_{4}$ & 0 \\
& $e_{2}$ & $e_{2}$ \\
& $-\alpha t_{1}-\beta t_{2}-(1-\beta) G$ & $-\alpha t_{1}-\beta t_{2}$ \\
\hline
\end{tabular}

\section{Replicator Dynamics Equation of the Tripartite Evolutionary Game}

Under the aforementioned assumption, the marginal expected revenue when doctors implement the ‘join’ strategy is $P_{11}$ :

$$
\begin{aligned}
P_{11}= & y z\left(r_{1}-c_{1}-c_{2}\right)+y(1-z)\left[r_{1}-c_{1}-c_{2}-(1-\alpha) c_{3}-(1-\beta) c_{4}\right]+ \\
& (1-y) z\left(-c_{1}\right)+(1-y)(1-z)\left[-c_{1}-(1-\beta) c_{4}\right]
\end{aligned}
$$

The marginal expected revenue when doctors implement the 'not join' strategy is $P_{12}$ :

$$
P_{12}=y z(0)+y(1-z)(0)+(1-y) z(0)+(1-y)(1-z)(0)
$$

The expected revenue of the doctors is $P_{1}$ : 


$$
P_{1}(x)=x P_{11}+(1-x) P_{12} .
$$

Thus, the replicator dynamics equation of doctors can be written as $P_{1}(x)$ in Formula (1):

$$
P_{1}(x)=\frac{\mathrm{d} x}{\mathrm{~d} t}=x(1-x)\left\{y\left[r_{1}-c_{2}-(1-\alpha) c_{3}\right]-c_{1}-(1-\beta) c_{4}+z(1-\beta) c_{4}\right\} .
$$

The marginal expected revenue when patients implement the 'use' strategy is $P_{21}$ :

$$
\begin{aligned}
P_{21}= & x z\left(e_{1}+e_{3}-h_{1}+L\right)+x(1-z)\left[e_{1}+e_{3}-h_{1}-(1-\alpha) h_{2}-(1-\beta)\left(h_{3}+h_{4}\right)\right] \\
& +(1-x) z\left(e_{2}\right)+(1-x)(1-z)\left[e_{2}-(1-\beta) h_{4}\right]
\end{aligned}
$$

The marginal expected revenue when patients implement the 'not use' strategy is $P_{22}$ :

$$
P_{22}=x z\left(e_{2}\right)+x(1-z)\left(e_{2}\right)+(1-x) z\left(e_{2}\right)+(1-x)(1-z)\left(e_{2}\right) .
$$

The expected revenue of the patients is $P_{2}$ :

$$
P_{2}(y)=y P_{21}+(1-y) P_{22} .
$$

Thus, the replicator dynamics equation of patients can be written as $P_{2}(y)$ in Formula (2):

$$
\begin{aligned}
P_{2}(y)= & \frac{\mathrm{d} y}{\mathrm{~d} t}=y(1-y)\left\{x\left[e_{1}-e_{2}+e_{3}-h_{1}-(1-\alpha) h_{2}-(1-\beta) h_{3}\right]\right. \\
& \left.+x z\left[(1-\alpha) h_{2}+(1-\beta) h_{3}+L\right]-(1-\beta) h_{4}+z(1-\beta) h_{4}\right\}
\end{aligned} .
$$

The marginal expected revenue when platforms implement the 'provide' strategy is $P_{31}$ :

$$
\begin{aligned}
P_{31}= & x y\left(w_{1}-t_{1}-t_{2}+M\right)+x(1-y)\left(-t_{1}-t_{2}\right) \\
& +(1-x) y\left(-t_{1}-t_{2}\right)+(1-x)(1-y)\left(-t_{1}-t_{2}\right)
\end{aligned} .
$$

The marginal expected revenue when platforms implement the 'not provide' strategy is $P_{32}$ :

$$
\begin{aligned}
P_{32}= & x y\left[w_{1}-\alpha t_{1}-\beta t_{2}-(1-\alpha) F_{1}-(1-\beta)\left(F_{2}+F_{3}+G\right)-N\right]+x(1-y)\left[-\alpha t_{1}-\beta t_{2}-(1-\beta) G\right] . \\
& +(1-x) y\left[-\alpha t_{1}-\beta t_{2}-(1-\beta) F_{3}\right]+(1-x)(1-y)\left(-\alpha t_{1}-\beta t_{2}\right)
\end{aligned}
$$

The expected revenue of the platforms is $P_{3}$ :

$$
P_{3}(z)=z P_{31}+(1-z) P_{32} .
$$

Thus, the replicator dynamics equation of platforms can be written as $P_{3}(z)$ in Formula (3):

$$
\begin{aligned}
P_{3}(z)= & \frac{\mathrm{d} z}{\mathrm{~d} t}=z(1-z)\left\{x y\left[M+(1-\alpha) F_{1}+(1-\beta) F_{2}+N\right]\right. \\
& \left.-(1-\alpha) t_{1}-(1-\beta) t_{2}+x(1-\beta) G+y(1-\beta) F_{3}\right\}
\end{aligned} .
$$




\section{Stability Analysis}

The above three replication dynamic equations describe the dynamic adjustment process of the strategy selection of doctors, patients and platforms. When the three groups continue to learn and imitate to reach the Nash equilibrium, it shows that the game system has reached a stable state. In order to find the stability point of the evolutionary game among the three stakeholders, we assume:

$$
\left\{\begin{array}{l}
\frac{\mathrm{d} x}{\mathrm{~d} t}=0 \\
\frac{\mathrm{d} y}{\mathrm{~d} t}=0 \\
\frac{\mathrm{d} z}{\mathrm{~d} t}=0
\end{array} .\right.
$$

Then within the range of the equilibrium solution domain $W=\{(x, y, z)|0 \leq x \leq 1 ; 0 \leq y \leq 1 ; 0 \leq z \leq 1|\}$, there are 8 special equilibrium solutions: $\mathrm{V} 0(0,0,0)$, V1 $(1,0,0), \mathrm{V} 2(1,1,0), \mathrm{V} 3(1,0,1), \mathrm{V} 4(0,1,0), \mathrm{V} 5(0,1,1), \mathrm{V} 6(0,0,1), \mathrm{V} 7(1,1,1)$. Another equilibrium point $E\left(x^{*}, y^{*}, z^{*}\right)$ is also in the above solution domain and satisfies:

$$
\begin{gathered}
y\left[r_{1}-c_{2}-(1-\alpha) c_{3}\right]-c_{1}-(1-\beta) c_{4}+z(1-\beta) c_{4}=0, \\
x\left[e_{1}-e_{2}+e_{3}-h_{1}-(1-\alpha) h_{2}-(1-\beta) h_{3}\right] \\
+x z\left[(1-\alpha) h_{2}+(1-\beta) h_{3}+L\right]-(1-\beta) h_{4}+z(1-\beta) h_{4}=0, \\
x y\left[M+(1-\alpha) F_{1}+(1-\beta) F_{2}+N\right] \\
\quad-(1-\alpha) t_{1}-(1-\beta) t_{2}+x(1-\beta) G+y(1-\beta) F_{3}=0 .
\end{gathered}
$$

Differentiate the three equations above to get:

$$
\begin{gathered}
P_{1}^{\prime}(x)=(1-2 x)\left[y\left(r_{1}-c_{2}-(1-\alpha) c_{3}\right)-c_{1}-(1-\beta) c_{4}+z(1-\beta) c_{4}\right], \\
P_{2}^{\prime}(y)=(1-2 y)\left\{x\left[e_{1}-e_{2}+e_{3}-h_{1}-(1-\alpha) h_{2}-(1-\beta) h_{3}\right]\right. \\
\left.+x z\left[(1-\alpha) h_{2}+(1-\beta) h_{3}+L\right]-(1-\beta) h_{4}+z(1-\beta) h_{4}\right\} \\
P_{3}^{\prime}(z)=(1-2 z)\left\{x y\left[M+(1-\alpha) F_{1}+(1-\beta) F_{2}+N\right]\right. \\
\left.-(1-\alpha) t_{1}-(1-\beta) t_{2}+x(1-\beta) G+y(1-\beta) F\right\}
\end{gathered}
$$


According to the stability theorem of the evolutionary game, when $P_{1}^{\prime}(x)<0, P_{2}^{\prime}(y)<0$, $P_{3}^{\prime}(z)<0$ in the above three formulas, $x^{*}, y^{*}$, and $z^{*}$ represent the stable strategies that doctors, patients, and platforms should adopt in the evolution process.

According to equation (4)

$$
y\left[r_{1}-c_{2}-(1-\alpha) c_{3}\right]-c_{1}-(1-\beta) c_{4}+z(1-\beta) c_{4}=0 .
$$

This equation represents the boundary of the steady state. When the following conditions are met:

$$
y\left[r_{1}-c_{2}-(1-\alpha) c_{3}\right]-c_{1}-(1-\beta) c_{4}+z(1-\beta) c_{4}>0 .
$$

Then, we get:

$$
P_{1}^{\prime}(0)>0, \quad P_{1}^{\prime}(1)<0 \text {. }
$$

This indicates that joining OHP is stable, and not joining OHP is unstable.

In contrast, when the following conditions are met:

$$
y\left[r_{1}-c_{2}-(1-\alpha) c_{3}\right]-c_{1}-(1-\beta) c_{4}+z(1-\beta) c_{4}<0 .
$$

Then, we get:

$$
P_{1}^{\prime}(0)<0, \quad P_{1}^{\prime}(1)>0 \text {. }
$$

This indicates that not joining OHP is stable, and joining OHP is unstable. When $x \in(0,1)$, $P_{1}(x)>0$. The phase evolution diagram of its stability depends on the shape of the quadratic curve of equation (4)

According to equation (5)

$$
\begin{aligned}
& x\left[e_{1}-e_{2}+e_{3}-h_{1}-(1-\alpha) h_{2}-(1-\beta) h_{3}\right] \\
& +x z\left[(1-\alpha) h_{2}+(1-\beta) h_{3}+L\right]-(1-\beta) h_{4}+z(1-\beta) h_{4}=0
\end{aligned}
$$

This equation represents the boundary of the steady state. When the following conditions are met:

$$
\begin{aligned}
& x\left[e_{1}-e_{2}+e_{3}-h_{1}-(1-\alpha) h_{2}-(1-\beta) h_{3}\right] \\
& +x z\left[(1-\alpha) h_{2}+(1-\beta) h_{3}+L\right]-(1-\beta) h_{4}+z(1-\beta) h_{4}>0
\end{aligned}
$$

Then, we get:

$$
P_{2}^{\prime}(0)>0, P_{2}^{\prime}(1)<0 \text {. }
$$

This indicates that using online medical treatment is stable, and not using online medical treatment is unstable. 
In contrast, when the following conditions are met:

$$
\begin{aligned}
& x\left[e_{1}-e_{2}+e_{3}-h_{1}-(1-\alpha) h_{2}-(1-\beta) h_{3}\right] \\
& +x z\left[(1-\alpha) h_{2}+(1-\beta) h_{3}+L\right]-(1-\beta) h_{4}+z(1-\beta) h_{4}<0
\end{aligned} .
$$

Then, we get:

$$
P_{2}^{\prime}(0)<0, P_{2}^{\prime}(1)>0 \text {. }
$$

This indicates that not joining online medical treatment is stable, and joining online medical treatment is unstable. When $x \in(0,1), P_{2}(x)>0$. The phase evolution diagram of its stability depends on the shape of the quadratic curve of equation (5).

According to equation (6)

$$
\begin{aligned}
& x y\left[M+(1-\alpha) F_{1}+(1-\beta) F_{2}+N\right] \\
& -(1-\alpha) t_{1}-(1-\beta) t_{2}+x(1-\beta) G+y(1-\beta) F=0 .
\end{aligned}
$$

This equation represents the boundary of the steady state. When the following conditions are met:

$$
\begin{aligned}
& x y\left[M+(1-\alpha) F_{1}+(1-\beta) F_{2}+N\right] \\
& -(1-\alpha) t_{1}-(1-\beta) t_{2}+x(1-\beta) G+y(1-\beta) F>0 .
\end{aligned}
$$

Then, we get:

$$
P_{3}^{\prime}(0)>0, \quad P_{3}^{\prime}(1)<0 .
$$

This indicates that using OHP is stable, and not using OHP is unstable.

In contrast, when the following conditions are met:

$$
\begin{aligned}
& x y\left[M+(1-\alpha) F_{1}+(1-\beta) F_{2}+N\right] \\
& -(1-\alpha) t_{1}-(1-\beta) t_{2}+x(1-\beta) G+y(1-\beta) F<0 .
\end{aligned}
$$

Then, we get:

$$
P_{3}^{\prime}(0)<0, \quad P_{3}^{\prime}(1)>0 \text {. }
$$

This indicates that not joining OHP is stable, and joining OHP is unstable. When $x \in(0,1)$, $P_{3}(x)>0$. The phase evolution diagram of its stability depends on the shape of the quadratic curve of equation (6).

\section{Results}


In order to explore the evolution of OHP under different parameter values, based on the established evolutionary game model, the platforms' QISC, IPISC, the initial state of doctors and patients, and the doctor's registration costs, time costs, reputation loss, and online healthcare costs of patients. We refer to the relevant data on the Spring Rain Doctor platform, consult experts who study simulation in related fields, and combine relevant literature research to determine the simulation parameters. These simulation parameters can reflect the general trend to some extent.

\section{The Influence of QISC $\alpha$ on the OHP Evolutionary Game Behavior}

$\alpha$ takes $0.1,0.5$ and 0.9 respectively for low QISC, medium QISC and high QISC.

As shown in Figure 3, due to the platforms' QISC is medium and low, doctors doubt the credibility of the platform. Finally, doctors will tend to the strategy of not joining OHP, and the lower the QISC, the faster the rate of evolution to the strategy of not joining. When the platform has a higher degree of QISC, doctors tend to believe the operation level of the platform. Therefore, OHP can improve the healthcare efficiency of doctors and their additional income. At last, doctors will tend to join OHP.

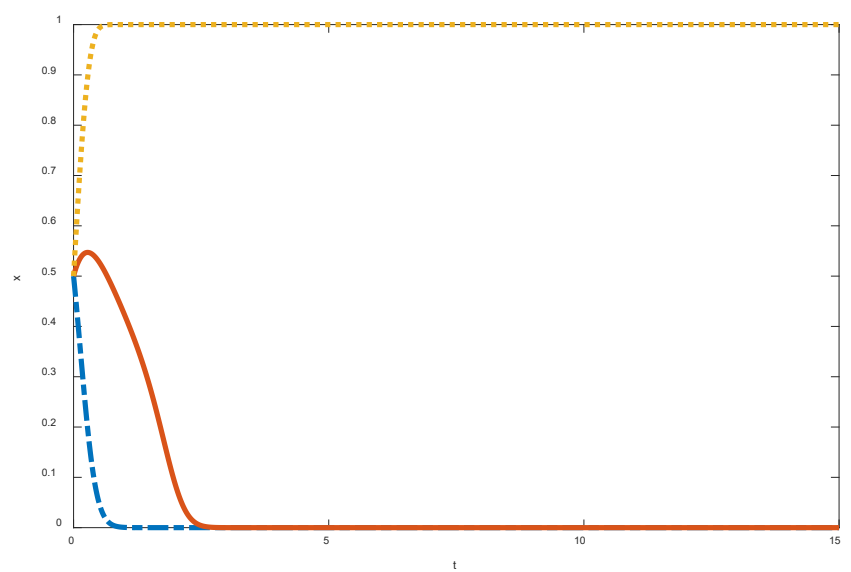

Figure 3. The evolution path of doctors' strategy under different QISC

As shown in Figure 4, when the platforms' QISC is low, patients doubt the healthcare level of the doctors on the platform and the reliability of the platform based on the doctors' information on the platform. Due to the fear of misdiagnosis, the patients' behavior will tend to the strategy of not using OHP. When the platforms' QISC is moderate, the patients will initially tend to not using OHP due to the psychology of observation. After that, patients can accurately judge the qualifications of doctors through the patient and peer evaluation mechanism on the platform, and tend to use OHP. 


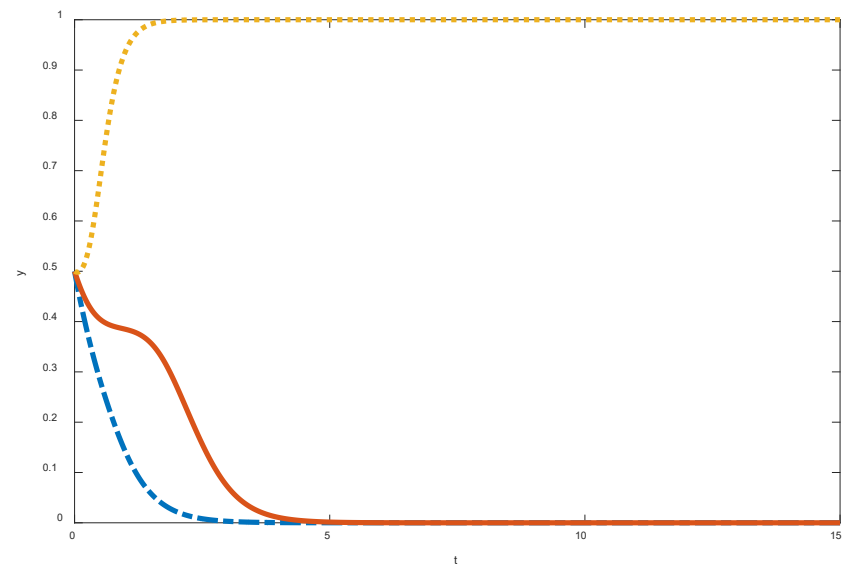

Figure 4. The evolution path of patients' strategy under different QISC

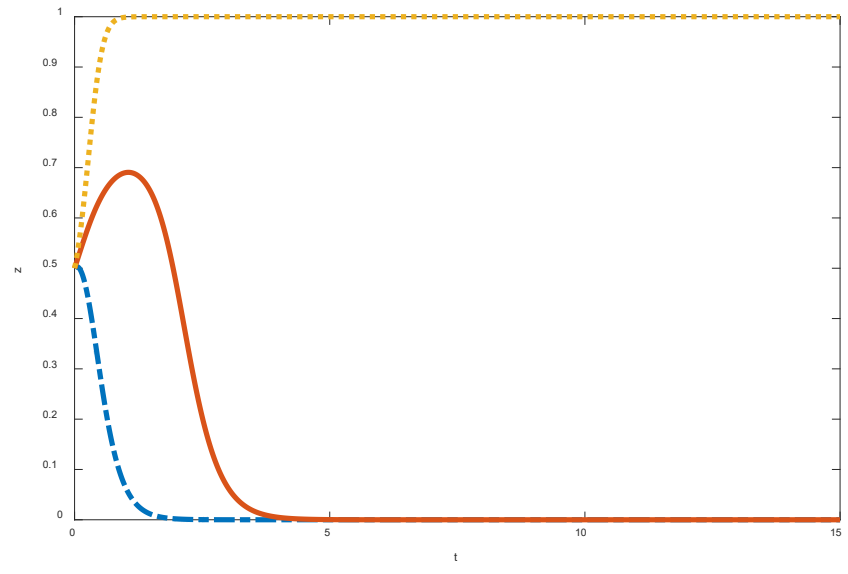

Figure 5. The evolution path of platforms' strategy under different QISC

When the platforms' QISC is high, patients can learn about the doctors' healthcare level through the doctor-related information published on the platform, such as the medical institution, region, and professional title. Because patients can save time and money by using OHP, at the same time, they can enjoy healthcare resources that were not previously available due to factors such as region and income level. Therefore, patients will tend to use OHP.

As shown in Figure 5, when the platforms' QISC is low, the platforms' inspection of doctors and the construction of the platform are relatively negative. Finally, the platform will tend to the strategy of not providing standardized online healthcare services.

When the platforms' QISC is moderate, because the platforms consider reputation, they will invest part of the funds to build the platforms' qualification inspection and information protection mechanism. However, over time the platforms' revenue is not as expected, and the platforms do not pay much 
attention to the brand and popularity. At last, platforms tend to the strategy of not providing standardized online healthcare services.

When platforms have a high degree of QISC, they pay more attention to its own construction, social reputation and long-term development. They invest heavily in doctor qualification inspection and information protection, and they are willing to take certain risks. Thus, the platforms eventually tend to provide standardized online healthcare services.

\section{The Influence of IPISC $\beta$ on OHP Evolutionary Game Behavior}

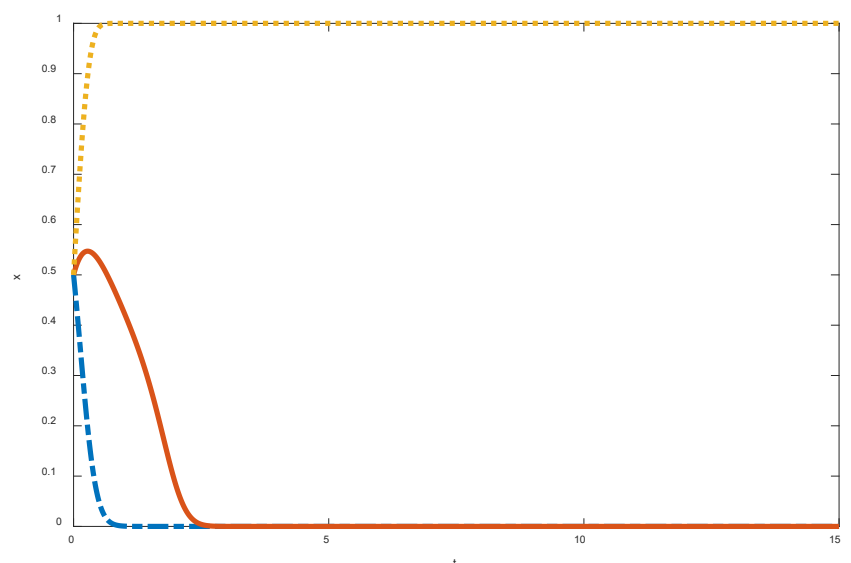

Figure 6. The evolution path of doctors' strategy under different IPISC

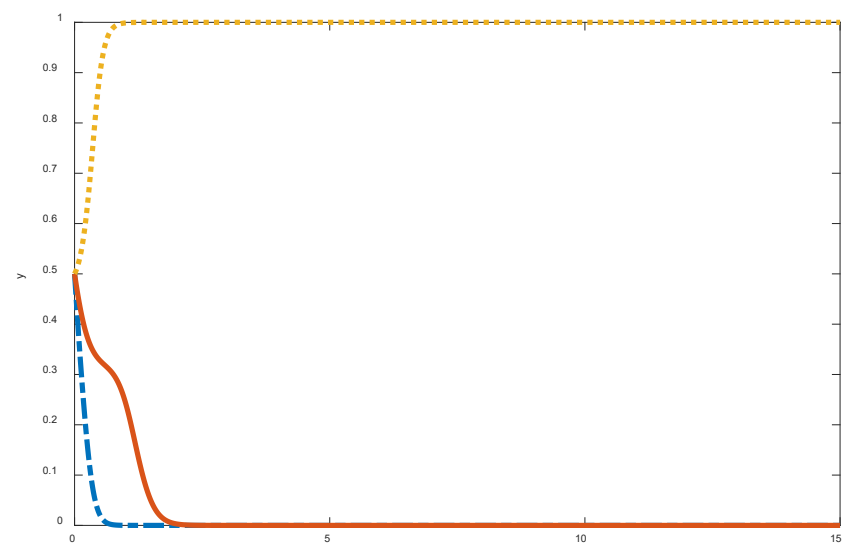

Figure 7. The evolution path of patients' strategy under different IPISC

$\beta$ takes $0.1,0.5$ and 0.9 respectively for low IPISC, medium IPISC, and high IPISC.

As shown in Figure 6, when the platforms' IPISC is low, doctors concern about their own information security, which will lead to the evolution of not joining OHP. 
When the platforms' IPISC is moderate, doctors will choose to join OHP for a period of time to observe the quality of the platforms' operation. However, the platforms' investment in information protection cannot meet the needs of doctors for their information security protection. Thus, the doctors finally choose not to join the OHP.

When the platforms invest heavily in information protection, doctors elect to trust the platforms' information protection mechanism and join OHP. And the greater the IPISC, the faster doctors elect to join OHP.

As shown in Figure 7, when the IPISC is low, patients concern about the leakage of private information and identity information, and they tend to elect not using OHP. The lower the platforms' IPISC, the faster the patients choose not to use it. When the platforms' IPISC is moderate or high, patients elect to trust the platforms' information protection mechanism and choose to use OHP.

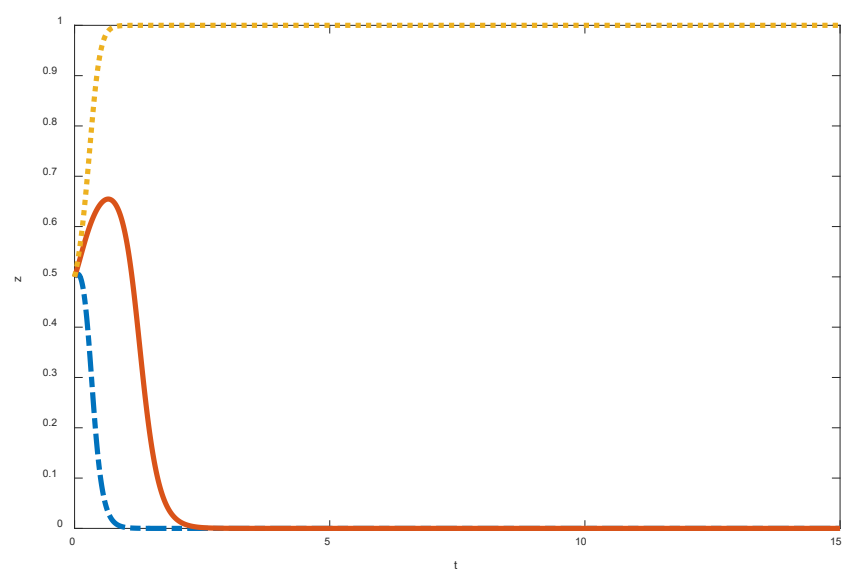

Figure 8. The evolution path of platforms's strategy under different IPISC

As shown in Figure 8, when platforms' IPISC is low, they lack attention to the construction of information protection mechanisms. Thus, the platforms ultimately choose not to provide standardized online healthcare services.

In the case of moderate investment in platform information protection, because the platforms want to attract doctors and patients, the platform initially elect to provide standardized online healthcare services. Over time, after a large number of doctors and patients join and use, the platform thinks there is no need to invest heavily in doctor qualification inspection and information protection because of the cost. Thus, platforms ultimately choose not to provide standardized online healthcare services.

When the platforms' IPISC is high, they pay more attention to the protection of doctors' and patients' privacy information and invest more funds to protect it. At this time, the platforms care more 
about long-term interests, so they choose to provide standardized online healthcare services. The higher the platforms' IPISC, the faster they choose to provide standardized online healthcare services.

\section{The Influence of Different Initial States of Doctors on the OHP Evolution Game Behavior}

As shown in Figure 9, when the probability that the doctors initially choose to join the OHP is 0.2 , doctors' attitude towards joining the OHP is negative. Therefore, patients concern about OHP and doubt the reliability of the platform. Eventually the patients elect not to use OHP. Because doctors do not join OHP, platforms cannot attract patients, and they quickly choose not to provide standardized online healthcare services.

When the probability that the doctors initially choose to join OHP is 0.9 , the doctors' willingness to join OHP is relatively strong, and there are a lot of doctors signing contracts with the platform at this time. The platform has very rich medical resources. These resources enable patients to trust the platforms, so they choose to use OHP. At this time the platform has a good thinking and they choose to provide standardized online healthcare services much faster than patients choose to use OHP.

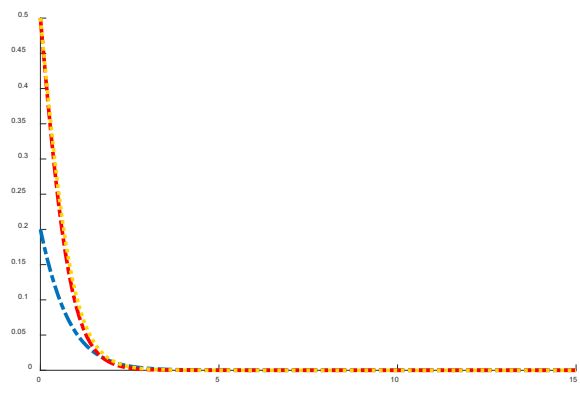

$x(1)=0.2$

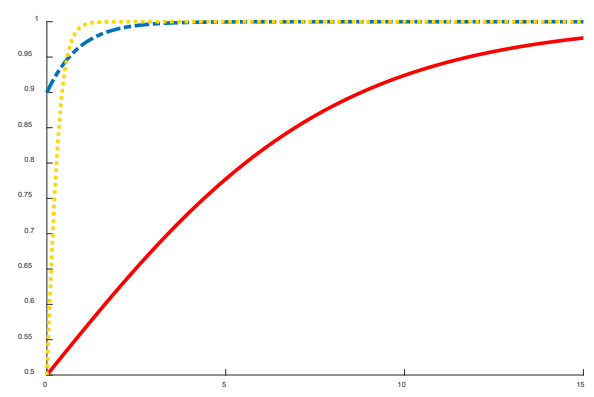

$x(1)=0.9$

Figure 9. The evolution track of three-party strategy selection under different initial states of doctors

\section{The Influence of Different Initial States of Patients on the OHP Evolution Game Behavior}

As shown in Figure 10, when the probability that the patients initially choose to use OHP is 0.2 , at this time, due to the platforms' operation, publicity and other factors, the patients' willingness to use OHP is low. OHP has not been popularized in the society. The platform lacks a large number of users. At this time, the platform is reluctant to spend too much cost on operating online healthcare services and tend to not provide standardized online healthcare services.

When the probability that patients initially choose to use OHP is 0.9 , most patients choose to use OHP. This form of OHP is popular among the public. At this time, a large amount of online medical 
resources is required. When a large number of patients choose to use OHP, the medical efficiency of doctors will be improved, and the pressure on hospitals will be reduced. Doctors can also obtain additional income. Therefore, doctors choose to join OHP. When a large number of users are registered on the platform, the platforms have the opportunity to obtain huge profits. They further improve the quality of platform services for their reputation and patients, strictly inspect the qualifications of doctors and actively protect the safety of patient information. At last, platforms tend to provide standardized online healthcare services.

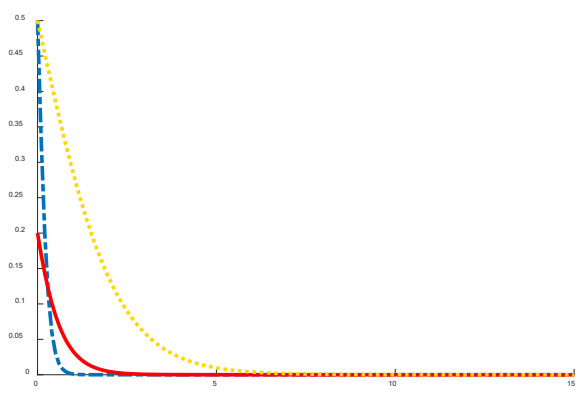

$y(1)=0.2$

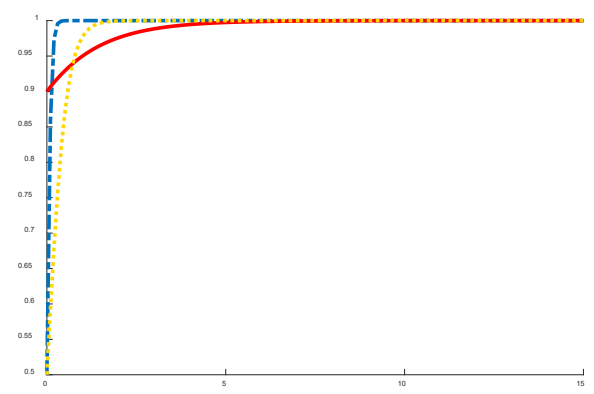

$y(1)=0.9$

Figure 10. The evolution track of three-party strategy selection under different initial states of patients

\section{The Influence of Different Registration Costs on the Evolutionary Behavior of Doctors}

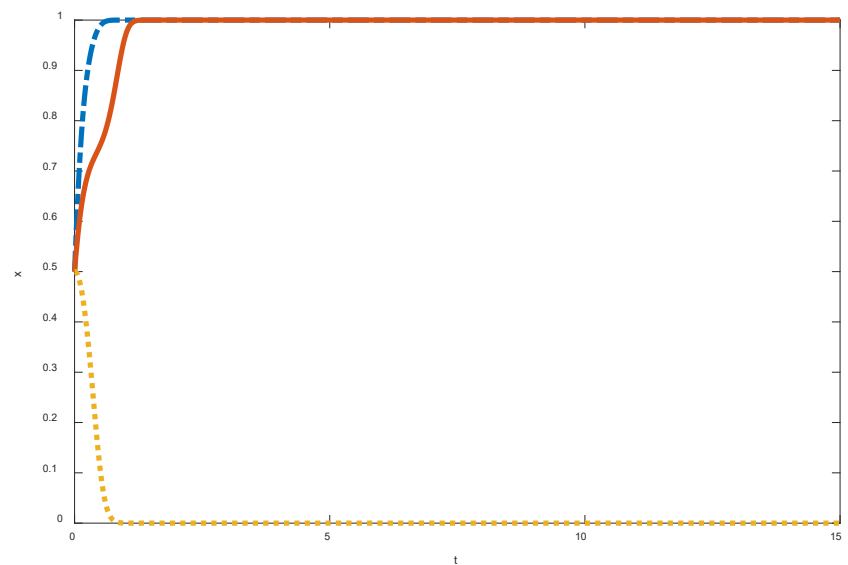

Figure 11. Evolutionary trajectory of doctor's strategy selection under different registration costs

As shown in Figure 11, when the qualification registration costs are high, doctors tend not to join OHP. Doctors are generally faced with the difficulty of registration. When inspecting the qualifications of doctors, the platforms require doctors to upload qualification certificates and work certificates. Some doctors think that the registration and cancellation procedures are very cumbersome. Therefore, they 
ultimately tend to not to join OHP. When the qualification registration costs are low, doctors tend to join OHP. This reflects that doctors' satisfaction and joining costs are important to the joining behavior of doctors.

The Influence of Different Time Costs on the Evolutionary Behavior of Doctors

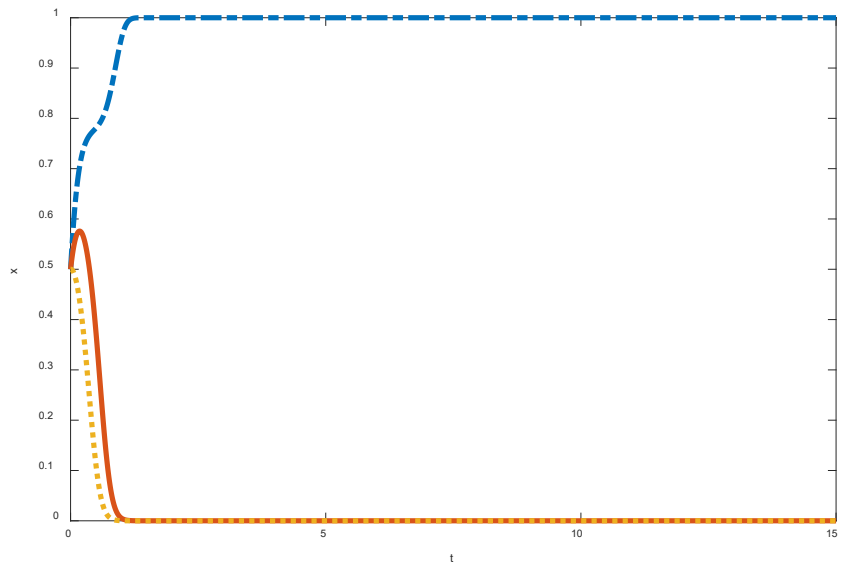

Figure 12. Evolutionary trajectory of doctors' strategy selection under different time costs

As shown in Figure 12, when the time costs are low, doctors are willing to use free time to join OHP to increase their income and reputation. Doctors can have online medical treatment at any time, which is one of the reasons why doctors choose to join OHP. When the time costs are medium, doctors try to choose to join at first, and then because of lack of time and energy, they finally elect not to join OHP. When the time costs are high, doctors tend to do their jobs in the hospital. At this time, they are unwilling to spend too much time on OHP, and ultimately choose not to join OHP.

\section{The Influence of Different Reputation Loss on the Evolutionary Behavior of Doctors}

As shown in Figure 13, when the reputation loss of doctors among patients is small, it is because the evaluation mechanism of patients on doctors set by the platforms is more reasonable and objective, and the professional level and working attitude of doctors can be fairly evaluated. At this time, the doctor has a greater willingness to join OHP. When the doctors' reputation is greatly lost, in addition to the medical level, the patients' requirements for the doctors' service level are also higher, and the doctor is more likely to receive negative evaluations about communication skills, timeliness and service attitudes. For example, the experience mechanism of doctors will be questioned by patients; patients are more willing to trust the opinions of doctors in offline hospitals than OHP; due to the availability of online knowledge, patients' psychological expectations for OHP are too high, which will lead to patients giving 
negative comments. Initially, doctors choose to join OHP. Over time, negative online reviews will put pressure on doctors, and they ultimately choose not to join OHP.

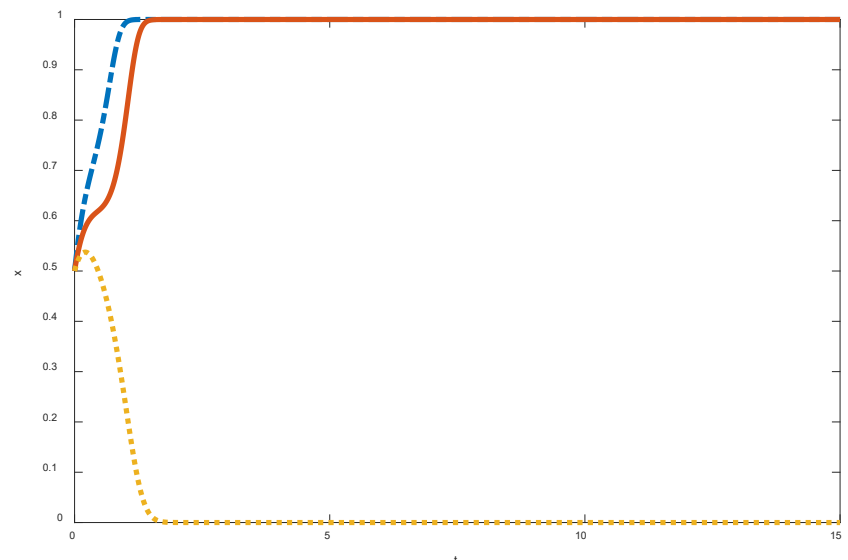

Figure 13. Evolutionary trajectory of doctors' strategy selection under different reputation loss

\section{The Influence of Different Online Healthcare Costs on the Evolutionary Behavior of Patients}

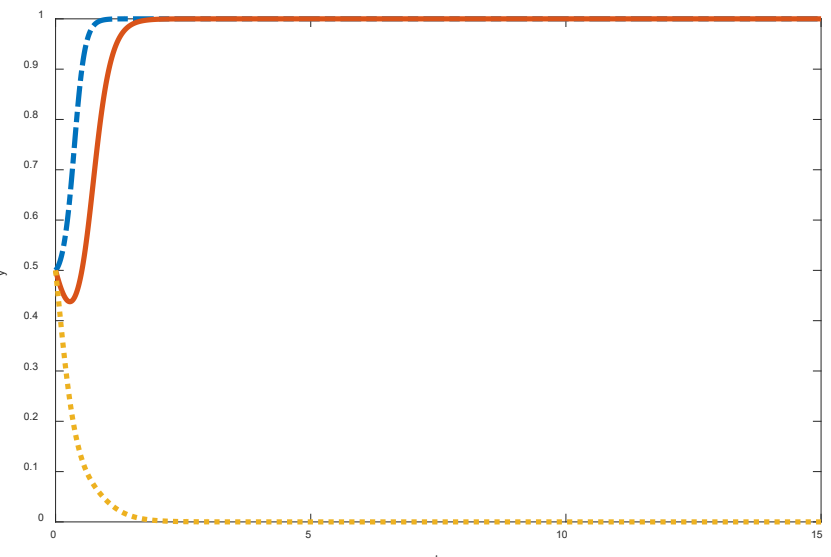

Figure 14. Evolutionary trajectory of patient's strategy selection under different online healthcare costs

As shown in Figure 14, when the online healthcare costs are low, since a large number of patients' conditions can be solved by simple diagnosis and treatment, using OHP can save patients time and money to go to the hospital for medical treatment. Especially, patients can reduce the costs of useless consultation through using OHP, and OHP can solve the problems of difficult and expensive medical treatment.

When the online healthcare costs are moderate, patients choose not to use OHP at the beginning. Because at the beginning people's awareness of paying for knowledge was not strong. However, with the passage of time, people's health concepts and consumption concepts have improved. The concept of 
obtaining high-quality healthcare services by paying lower medical expenses than that of hospitals has gradually become popular among patients. Eventually patients elect to use OHP.

When online healthcare costs are high, although OHP have been rapidly promoted and patients have gradually accepted this medical method due to the convenience, patients have not yet established trust in the platforms and doctors. Many factors make patients doubt the professionalism of doctors and the reliability of platforms. When OHP cannot help patients save the cost of seeing a doctor, patients tend not to use OHP.

\section{Case Analysis: An Example of Spring Rain Doctor Platform}

Spring Rain Doctor which has been developing for nearly 8 years since 2011 is the first Internet enterprise in China to try online healthcare. More than 300 public hospitals have settled in the platform. By the end of August 2020, the platform has 630,000 Chinese practicing doctors from all departments. The cumulative number of users of the platform is 130 million, and its daily consulting times exceeds 300,000. It is the world's largest mobile doctor-patient communication platform. Doctors could converse with patients through the website, pictures, mobile phones, and even video format. In addition, doctors could observe timely feedback and service assessments of patients [31].

Table 3. The proportion of users in each province

\begin{tabular}{cc}
\hline Province & The proportion of users in each province(\%) \\
\hline Guangdong & $11.2 \%$ \\
Shandong & $7.16 \%$ \\
Hebei & $6.05 \%$ \\
Jiangsu & $5.85 \%$ \\
Sichuan & $5.45 \%$ \\
Zhejiang & $4.94 \%$ \\
Henan & $4.94 \%$ \\
Liaoning & $4.54 \%$ \\
Heilongjiang & $4.04 \%$ \\
Hubei & $3.43 \%$ \\
\hline
\end{tabular}

According to the data provided by Artery Network, the Table 3 shows the proportion of platform users in each region. Guangdong has the largest number of users, accounting for $11.2 \%$, far more than other regions; followed by Shandong, accounting for $7.16 \%$. The reason for this phenomenon may be that Guangdong is a young city, and people are more interested in new things and are willing to try new 
medical methods. Moreover, the per capita income in the region is relatively high, and people's time and opportunity costs are huge. If users can consult online at any time and save the time and cost of going to the hospital, they will be more willing to pay for consultation on the platform. Combining the population numbers of each province in 2018 in Table 4, eight of the top ten provinces with the number of users of Spring Rain Doctor platform are among the top ten provinces by population. It can be inferred that the population of Spring Rain doctors is evenly distributed across the country, and the population of platform users is not restricted by region. This shows that various regions have the problem of lack of medical resources. Different regions have different problems. For example, developed regions have more medical resources, but the number of patients is large and it is difficult to see a doctor. In rural areas, medical resources are scarce and it is expensive for patients to see a doctor.

Table 4. The top 10 provinces in population in 2018

\begin{tabular}{ccc}
\hline & Province & Population(million) \\
\hline 1 & Guangdong & 111.69 \\
2 & Shandong & 100.05 \\
3 & Henan & 95.59 \\
4 & Sichuan & 83.02 \\
5 & Jiangsu & 80.29 \\
6 & Hebei & 75.19 \\
7 & Hunan & 68.60 \\
8 & Anhui & 62.54 \\
9 & Hubei & 59.02 \\
10 & Zhejiang & 56.57 \\
\hline
\end{tabular}

Online healthcare services are one of the "standard configurations" of various mobile medical enterprises. This is also one of the most competitive areas. However, only the most reliable and reliable medical resources are the most powerful competitive forces. In response, Dr. Wang Jianguo, Vice President of Spring Rain Doctor, released the "Online Diagnosis and Treatment Ability Report" at the meeting. Spring Rain Doctor solves more than 330,000 health problems daily, with an average response time of about 3 minutes. The source of doctors covers all provinces (autonomous regions, municipalities directly under the Central Government) except Hong Kong, Macao and Taiwan. Most doctors are between the ages of $25-45$, senior doctors account for $24 \%$, and other doctors are $38 \%$. In terms of doctor qualifications, Spring Rain Doctor has a strict inspect mechanism. First, it requires four cards, namely real-name information such as a doctor's qualification certificate, a practicing qualification certificate, 
an ID card, and a bank card. Then there will be staff to confirm the doctor's work by phone or offline to confirm that the doctor is indeed a working doctor. At the same time, the most active and largest group of Spring Rain Doctor comes from the upper first-class hospitals. According to the data provided by Artery Network, the figure 15 shows the number of online doctors from the upper first-class hospitals was 4,680 , accounting for $62.3 \%$ of the online doctors. This means that the Spring Rain Doctor platform has a large number of high-quality medical resources. In addition, when the doctor serves online, there will also be a strict evaluation mechanism. This shows that the platform's inspection of doctor qualifications is an important factor affecting the platform's online healthcare competitiveness. The conclusions in Figure 3 to Figure 5 are verified.

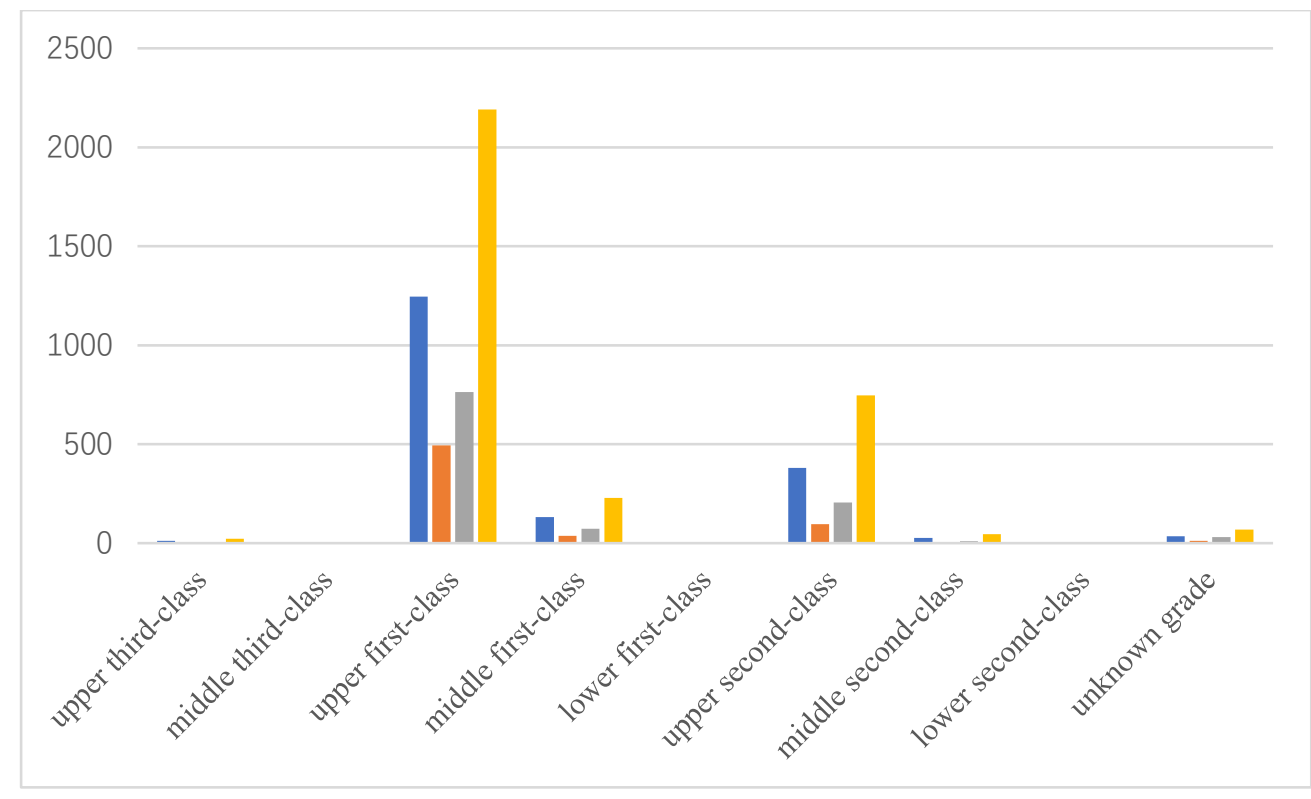

Figure 15. Number of online doctors at all levels

On the protection of privacy information, the general Office of the State Administration for Market Regulation (SAMR), the Secretariat of the Cyberspace Administration of China, Ministry of Industry and Information Technology of the People's Republic of China (MIIT) and the General Office of the Ministry of Public Security (MPS) jointly issued the Method for Determining the Illegal Collection and Use of Personal Information by APPS on December 30, 2019. Spring Rain Doctor and 10 other apps were reported for illegally collecting and using personal information, because they didn't make clear to the users to apply for all privacy rights. Users ask about privacy diseases on the Spring Rain Doctor platform to avoid being discovered by acquaintances. After that, the Spring Rain Doctor APP launched a privacy policy. Therefore, the protection of the platform's information is an important factor for patients 
to choose to use OHP. If the platform violates the privacy of patient users, it will result in the loss of a large number of users. The conclusions in Figure 6 to Figure 8 are verified.

In 2016, as the largest online consultation platform in the country, Spring Rain Doctor set up the online consultation service function of Spring Rain Doctor for hardware manufacturers, APPs, websites, WeChat accounts, etc. who have this demand for free. After the opening of Spring Rain Doctor's online consultation platform, Spring Rain Doctor uses this borderless online consultation portal to dig deeper into the platform's online consultation capabilities, strengthen the "foundation" role of this service for mobile healthcare, and strive to become the second entrance to health issues of Chinese. By expanding Spring Rain Doctor's online healthcare portal, patients can use online healthcare functions more conveniently and the popularization of Spring Rain Doctor online healthcare functions can be promoted consequently. This shows that Spring Rain Doctor promotes online healthcare as much as possible to increase the probability of patients using OHP. The conclusions in Figure 10 are verified.

Spring Rain Doctor initially interviewed doctors through the offline team to obtain medical resources one by one. After the brand is be promoted, the number of doctors added through the brand effect exceeded the number of doctors promoted. In order to obtain a large number of doctor resources, so that patients no longer have the problem of shortage of medical resources, Spring Rain Doctor provides different patients for doctors by layering the needs of users, or puts doctors with different capabilities and different services on different platforms. So that the doctor and patient can get a good match. At the same time, in order to make doctors more likely to join, Spring Rain Doctor reduces the registration cost of doctors. Spring Rain Doctor's registration and auditing are more user-friendly, especially auditing, supporting everyone to use badges, work permits to replace qualification certificates and some complicated proofs. This reduces the doctor's registration costs and difficulty of using, while ensuring the authenticity of the doctor's qualifications. This shows that reducing the registration costs of doctors is also a way for the platform to attract doctors to join. The conclusions in Figure 11 are verified. According to the data provided by Artery Network, as of September 2014, the income of doctors on the Spring Rain Doctor platform is shown in Table 5. The doctor's income is divided into two parts. One part is the income obtained by answering users' free consultations, and this part of the income is paid by Spring Rain Doctor platform. The platform paid the doctor 1.5 yuan for each reply. The second part is the dynamic pricing part of doctors, and all the income of this part is paid by users. It should be noted that since the dynamic pricing part of doctors' income has been changing, there may be a large gap 
between the data and the doctor's actual income. But it can be seen that the Spring Rain Doctor platform attracts more doctors to join through subsidies to doctors. This will make the Spring Rain Doctor platform's doctors more active and attract a large number of users. In summary, the Spring Rain Doctor platform uses various methods to increase the probability of doctors joining. The conclusions in Figure 9 are verified.

Table 5. Income of each department on Spring Rain Doctor platform

\begin{tabular}{cc}
\hline Department & Income(million) \\
\hline Pediatrics & 2.48 \\
Otolaryngology & 0.56 \\
Obstetrics and Gynecology & 2.98 \\
Orthopedics & 0.68 \\
Stomatology & 0.34 \\
Male Urology & 1.56 \\
Cranial Nerve & 0.85 \\
Endocrinology & 0.45 \\
Internal Medicine & 3.84 \\
Dermatology & 1.48 \\
Surgery & 2.30 \\
Psychology & 0.54 \\
Cardiovascular & 0.75 \\
Ophthalmology & 0.42 \\
Nutritional & 0.14 \\
Plastic Surgery & 0.40 \\
Chinese Medicine & 0.52 \\
Oncology & 0.46 \\
Grand Total & 20.76 \\
\hline
\end{tabular}

The most important purpose for doctors to join OHP is to increase economic and reputational benefits. Through research, the doctors on the platform of Spring Rain Doctor report that the platform arbitration is biased towards users when disputes occur between doctors and patients; Spring Rain Doctor's doctor evaluation system drop more points than other platforms; It is often the case that doctors didn't respond in time and receive bad reviews. These problems have dampened the enthusiasm of doctors. The common point of these problems is that they damage the reputation of doctors. Therefore, the loss of the reputation of doctors is an important factor for doctors to consider whether to join OHP. The conclusions in Figure 13 are verified. 
According to the data in Figure 16, the users of Spring Rain Doctor platform are concentrated in the middle of the consumption level. This shows that OHP is more acceptable to the general public. However, users below the medium consumption level account for more than $50 \%$ of all users. This shows that online healthcare costs are still a key factor for patients to use the Spring Rain Doctor platform. The conclusions in Figure 14 are verified.

According to the user survey report of Spring Rain Doctor platform (data from www.woshipm.com), the website interviewed doctors in depth. A part of survey questions and interview results are shown in Table 6. Table 6 shows that income and word of mouth are the main motivations for doctors to join OHP, and time cost is the main factor affecting doctors' joining behavior. The conclusions in Figure 12 are verified.

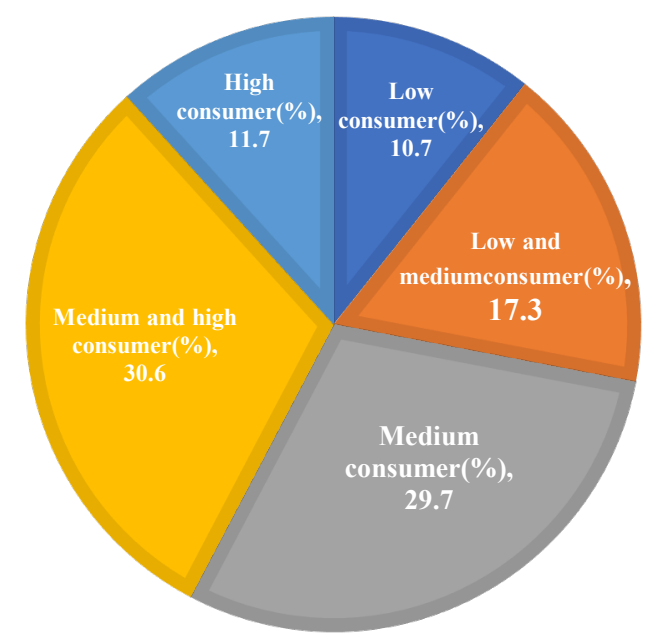

Figure 16. Analysis on the consumption ability of Spring Rain Doctor's users

Table 6. A part of survey questions and interview results

\begin{tabular}{|c|c|}
\hline Question & Result \\
\hline $\begin{array}{c}\text { Do you provide private doctor } \\
\text { services? }\end{array}$ & $\begin{array}{l}\text { We can provide the services of a private doctor when we } \\
\text { have the time and energy. But we do not want to take up } \\
\text { too much working time. }\end{array}$ \\
\hline $\begin{array}{l}\text { What is your motivation for online } \\
\text { health services? }\end{array}$ & $\begin{array}{l}\text { We can use our free time to increase revenue and } \\
\text { reputation. }\end{array}$ \\
\hline $\begin{array}{l}\text { Have you ever received negative } \\
\text { reviews when providing online health } \\
\text { services? }\end{array}$ & $\begin{array}{l}\text { The main reason we received bad reviews was that we } \\
\text { did not respond in time. }\end{array}$ \\
\hline $\begin{array}{l}\text { What are your requirements and } \\
\text { suggestions for the platform? }\end{array}$ & $\begin{array}{l}\text { Users can clearly explain the complete symptoms at one } \\
\text { time during consultation, thereby saving time. }\end{array}$ \\
\hline
\end{tabular}




\section{Discussion}

This paper establishes a game model for the evolution of the players in the online medical field based on the premise of the bounded rationality of the game party. Through the analysis of the threeparty evolution game model and the numerical simulation analysis of the evolutionary behavior of doctors, patients and platforms, we found that the higher the platforms' inspection of doctor qualifications, the more it can strengthen the trust of doctors and patients to the platform, and promote the participation and use of doctors and patients. Low and medium intensity scrutiny will cause doctors and patients to choose not to join or use it because of fear of misdiagnosis. In the existing literatures, some scholars have mentioned that OHP employ doctors to answer patient questions, and high quality OHP are more likely to be acknowledged by patients [27]. Therefore, for patients, they can easily and quickly obtain high-quality medical resources such as doctors in the third-class hospital by using OHP. The lack of medical resources and the uneven distribution are important reasons for patients to use OHP. The greater the platforms' inspection of medical resources, the better the quality of doctors can be guaranteed, which improves the patients' trust in the platforms, avoids misdiagnosis and other issues, and improves the platforms' credibility, thereby forming a benign circulatory system. In addition, the high inspection strength of the platform also has an incentive effect on the platform itself, making the platform unwilling to give up sunk costs and promoting the high-quality development of the platform.

When the platforms' privacy information protection is moderate or low, doctors and patients tend to choose not to join or use OHP. The greater the protection of the platforms' information, the more able to promote doctors and patients to join and use OHP. Indeed, there has been evidence in the literature indicating that patients may hesitate to disclose their personal information online so they switch doctors frequently or switch to an offline hospital visit [6]. Thus, the platforms' information protection mechanism is an important factor in whether the doctors and patients choose OHP. The competent government department should clarify the entry threshold for OHP as soon as possible, improve the information security management system, ensure user information security and privacy, and better play the role of OHP.

For doctors, the stronger the patients' willingness to use OHP, the more inclined the doctors to join OHP, thereby obtaining more benefits. At the same time, registration costs, time costs, and reputation loss all affect whether doctors join OHP. It is proved that if a doctor provides a satisfactory service online, it may help his/her simultaneously gain reputation from both online and offline channels through word 
of mouth communication [31]. Rather, when doctors decide to offer online counseling services in their free time, the number of consultations and extra devoted time are considered to be negative factors affecting doctors' initiatives [31]. Without proper stimulating motivators, joining in OHP is stressful for doctors because they have a heavy work in hospitals [30].

For patients, the richer the medical resources and the higher the quality of the platforms, and the lower the costs of OHP, the more they can encourage patients to use OHP, saving more time and money costs. Previous studies have confirmed that online consultation can provide patients with convenient access to physicians at low cost [11]. Therefore, the platforms should vigorously promote OHP, so that more doctors can actively join in, thereby attracting more patients. There are many ways to promote OHP, but grassroots doctors are the entrance with the highest conversion rate. Grassroots doctors can connect medical resources and patients to a certain extent, which will be a key part of the cross-border integration of the Internet and the medical industry. The platform should concentrate high-quality resources on grassroots doctors, provide them with certain training opportunities and room to learn, and increase the income of grassroots doctors. At the same time, the platform should improve the doctors' review and evaluation mechanism, such as simplifying the review and registration process, making the process more user-friendly and more convenient; optimizing the operation process function, and adding online and offline to the doctor in the graphical consultation interface Status setting function, so that patients will not give bad reviews to doctors because of the long waiting time; adding the functions of message withdrawal, message copy, sending small video, voice to text, service end countdown, remaining number of conversations, and the other party's reply status in the dialog box between the two parties, so that the upper limit of the number of conversations in the service time limit can be reduced; using technology to improve the communication efficiency of doctors and patients, reduce the reputation loss and time cost of doctors, and make reasonable use of limited and precious medical resources. In addition, the core of OHP promotion is the patient. For China, remote cities and township residents are the largest customer groups of OHP. The OHP is just a new form of service in the medical industry. Promoting the popularization of OHP in remote and township residents can make the value of OHP form truly reflected, thus promoting the development of the entire mobile medical industry. Therefore, the platforms should increase publicity and advertising in remote cities and rural township residents to attract more medical workers to join the OHP field. 
Although we found some implication of OHP promotion, there still work need to do in the future. For example, we can study the behavior of OHP subjects from the perspective of government regulation, and whether free consultation will affect the enthusiasm of doctors. In the future, we need to include the government into the scope of OHP subjects to further study the promotion of OHP.

\title{
Conclusion
}

In this paper, through the establishment of an evolutionary game model of OHP stakeholders, we found that the platforms' qualification inspection of doctors, investment in information protection, initial probability of doctors joining, initial probability of patients using, doctors' registration costs, time costs, reputation loss, and the online healthcare costs of patients have an impact on the three parties' strategic choices. The three stakeholders influence each other's behavior. Therefore, the platforms should pay attention to doctor qualification and information protection, improve the platform function and patient evaluation mechanism, and set reasonable prices of online healthcare treatment. At the same time, the government should increase supervision, regulate the behavior of the platform, clarify the distribution of responsibility for online healthcare legal issues, and promote the healthy development of OHP.

\author{
Abbreviations \\ OHP: Online Healthcare Platform \\ QISC: Qualification Inspect Strength Coefficient \\ IPISC: Information Protection Investment Strength Coefficient
}

\section{Ethics approval and consent to participate}

Not applicable

\section{Consent for publication}

Not applicable

\section{Availability of data and materials}

The datasets generated and analyzed during the current study are not publicly available due individual privacy but are available from the corresponding author on reasonable request.

\section{Competing interests}

The authors declare no competing interests.

\section{Funding}


This research was supported by three funds: 1) National Natural Science Foundation of China: Evolution Mechanism, Model and Policy of Industry-University-Research Cooperation Innovation Network (grant number: 71473055); 2) Heilongiiang Province Philosophy and Social Science Research Project: Research on Responsible Innovation Mechanism of Emerging Technologies and Its Adaptive Governance (grant number: 19GLH045); 3) Fundamental Research Funds for the Central Universities: Research on Artificial Intelligence Technology Responsibility Innovation Mechanism and Governance(grant number: 3072020CFW0902); 4) The Ph.D. Student Research and Innovation Fund of the Fundamental Research Funds for the Central Universities (3072019GIP0909).

\section{Authors' contributions}

Conceptualization, Cao, X.; methodology, Zhang, L.T.; software, Lv, D. and Xing, Z.Y.; data curation, Li, W.J.; writing, Zhang, L.T. All authors have read and agreed to the published version of the manuscript.

\section{Acknowledgements}

We would like to thank the participants for their contribution to this work.

\section{References}

1. Varshney, U. Pervasive healthcare. Computer. 2003; 36(12):138-40.

2. Hu, Y.R.. How does freemium strategy affect the demand of the paid premium mobile healthcare service: From an information asymmetry perspective. Information Development. 2019; 35(1):36-50.

3. Jung, C.; Padman, R. Disruptive Digital Innovation in Healthcare Delivery: The Case for Patient Portals and Online Clinical Consultations. The Handbook of Service Innovation. 2015; https://doi.org/10.1007/978-14471-6590-3_15.

4. Whitten, P.; Buis, L.; Love, B. Physician-Patient e-Visit Programs: Implementation and Appropriateness. Disease Management \& Health Outcomes. 2007; 15(4):207-214. 
5. Le, W.; Chang, P.Y.; Chang, Y.W.; Chen, J.H. Why Do Patients Move from Online Health Platforms to Hospitals? The Perspectives of Fairness Theory and Brand Extension Theory. International Journal of Environmental Research and Public Health. 2019; 16:3755.

6. Yang, Y.F.; Zhang, X.F.; Lee, P.K.C. Improving the effectiveness of online healthcare platforms: An empirical study with multi-period patient-doctor consultation data. International Journal of Production Economics. 2019; 207: 70-80.

7. Lu, X.Y.; Zhang, R.T.; Zhu, X.M. An Empirical Study on Patients' Acceptance of Physician-Patient Interaction in Online Health Communities. International Journal of Environmental Research and Public Health. 2019; 16:5084.

8. Li, Y.F.; Song, Y.Y.; Zhao, W.; Guo, X.T.; Ju, X.F.; Vogel D. Exploring the Role of Online Health Community Information in Patients' Decisions to Switch from Online to Offline Medical Services. International Journal of Medical Informatics. 2019; 130:103951.

9. Wu, H.; Lu, N.J. Service provision, pricing, and patient satisfaction in online health communities. International Journal of Medical Informatics. 2018; 110:77-89.

10. Deng, Z; Liu, S. Understanding consumer health information-seeking behavior from the perspective of the risk perception attitude framework and social support in mobile social media websites. International Journal of Medical Informatics. 2017; 105:98-109

11. Cao, X.Y.; Liu, Y.M.; Zhu, Z.X.; Hu, J.H.; Chen, X.H. Online selection of a physician by patients: Empirical study from elaboration likelihood perspective. Computers in Human Behavior. 2017; 73:403-412.

12. Guo, X.T.; Guo, S.S.; Vogel, D.; Li, Y.J. Online healthcare community interaction dynamics. Journal of Management Science and Engineering. 2016; 1:58-74.

13. Li, C.R.; Zhang, E.; Han, J.T. Exploring the effect of market conditions on price premiums in the online health community. International Journal of Environmental Research and Public Health. 2020; 17(4):1326

14. Luo, Y.; Chen, X.; Sun, Y.Y. A Fuzzy linguistic method for evaluating doctors of online healthcare consultation platform using BWM and prospect theory. 2019 IEEE 6th International Conference on Industrial Engineering and Applications (ICIEA). 2019.

15. Zhang, S.C.; Feng, G.Z. Research on the supervision of mobile medical APP. Modern Business Trade Industry 2019; 40(11):90-91. (in Chinese)

16. Zhu G.; Liu, H.; Chen, J.; Du, X.M. Privacy accountability analysis of mobile health service based on evolutionary game theory. Journal of Modern Information. 2018; 38(12):32-39. (in Chinese)

17. Yang, Y.F.; Yu, Yang; Zhang, H.X.; Wang, W.J. Analysis of the problems and solutions of mobile medical APP. Economist. 2019; 359(01):231-232. (in Chinese)

18. Deng, Z.H.; Mo, X.T.; Liu, S. Comparison of the middle-aged and older users' adoption of mobile health services in China. International Journal of Medical Informatics. 2014; 83(3):210-224. 
19. Lu, N.J.; Wu, H. Exploring the impact of word-of-mouth about Physicians' service quality on patient choice based on online health communities. BMC Medical Informatics and Decision Making. 2016; 16:151.

20. Sun, J.B.; Lu, J.J. An empirical study on user acceptance of healthcare website. An empirical study on user acceptance of healthcare website. International Journal of Networking and Virtual Organisations. 2014; 14:5773.

21. Veer, A.J.E.; Peeters, J.M.; Brabers, A.E.; Schellevis, F.G.; Rademakers, J.J.; Francke, A.L. Determinants of the intention to use e-health by community dwelling older people. BMC Health Services Research. 2015; 15: $1-9$.

22. Jung, C.; Padman, R. Virtualized healthcare delivery: Understanding users and their usage patterns of online medical consultations. International Journal of Medical Informatics. 2014; 83(12):901-914.

23. Chang, Y.W.; Hsu, P.Y.; Wang, Y.; Chang, P.Y. Integration of online and offline health services: The role of doctor-patient online interaction. Patient Education and Counseling. 2019; 102:1905-1910.

24. Wu, Bing. Patient continued use of online health care communities: web mining of patient-doctor communication. Journal of Medical Internet Research. 2018; 20: e126.

25. Gu, D.X.; Yang, X.J.; Li, X.G.; Jain, H.K.; Liang, C.Y. Understanding the role of mobile internet-based health services on patient satisfaction and word-of-mouth. International Journal of Environmental Research and Public Health. 2018; 15:1972.

26. Amin, I.M.; Hussein, S.S.; Isa, W.A. Assessing user satisfaction of using hospital information system (HIS) in Malaysia. International Proceedings of Economics Development and Research. 2011; 5(1):210.

27. Guo, S.S.; Guo, X.T.; Fang, Y.L.; Vogel, D. How doctors gain social and economic returns in online healthcare communities: A professional capital perspective. Journal of management information systems. 2017; $34(2): 487-519$.

28. Liu, Q.B.; Liu, X.; Guo, X. The effects of participating in a physician-driven online health community in managing chronic disease: evidence from two natural experiments. MIS Quarterly. 2020; 44(1):391.

29. Li, J.; Wu, H.; Deng, Z.; Lu, N.; Evans, R.; Xia, C. How professional capital and team heterogeneity affect the demands of online team-based medical service. BMC Medical Informatics and Decision Making. 2019; 19(1):119.

30. Yang, H.L.; Du, H.S.; He, W.; Qiao, H. Understanding the motivators affecting doctors' contributions in online healthcare communities: professional status as a moderator. Behaviour \& Information Technology.2019; DOI: 10.1080/0144929X.2019.1679887

31. Chen, J.H.; Lan, Y.C.; Chang, Y.W.; Chang, P.Y. Exploring doctors' willingness to provide online counseling services: the roles of motivations and costs. International Journal of Environmental Research and Public Health. 2020; 17(1): 110 . 
32. Ma, C.Y.; Wang, Q.Z. An empirical study on physicians' willingness to adopt online medical service platform and its influencing factors. China Journal of Health Policy. 2018;11(06):68-73. (in Chinese)

33. Yang, H.L.; Zhang, X.F. Investigating the Effect of Paid and Free Feedback on Patients' and Physicians' Behaviors: Panel Data Analysis. Journal of Medical Internet Research. 2019; 21 (3): e12156.

34. Liu, S.; Zhang, M.Y.; Gao, B.J.; Jiang, G.Y. Physician voice characteristics and patient satisfaction in online health consultation. Information \& Management. 2020; 57(5):103233.

35. Li, J.Y.; Deng, Z.H.; Evans, R.; Liu, S.; Wu, H. How doctors take initiatives in online healthcare communities. Industrial Management \& Data Systems. 2020; 120(7):1401-1420.

36. Yang, H.L.; Guo, X.T.; Wu, T.S.; Ju, X.F. Exploring the effects of patient-generated and system-generated information on patients' online search, evaluation and decision. Electronic Commerce Research and Applications. 2015; 14(3):192-203.

37. Mcgeady, D.; Kujala, J., Ilvonen, K. The impact of patient-physician web messaging on healthcare service provision. International Journal of Medical Informatics. 2008; 77:17-23.

38. Goh, J.M.; Gao, G.D.; Agarwal, R. The creation of social value: Can an online health community reduce ruralurban health disparities. MIS Quarterly. 2016; 40(1):247-263.

39. Venkatesh, V.; Rai, A.; Sykes, T.A.; Aljafari, R. Combating infant mortality in rural India: Evidence from a field study of e-health kiosk implementations. MIS Quarterly. 2016; 40(2):353-380.

40. Wu, J.; Zhou, L.S. The trans-regional flow of medical information resources: The study of online health communities' role in optimizing allocation of medical resource. Journal of Information Resources Management. 2017; 7:58-65+85.

41. Smith, J.M. The theory of games and the evolution of animal conflicts. Journal of Theoretical Biology. 1974; 47(1):209-221.

42. Li, D.F. Linear programming approach to solve interval-valued matrix games. Omega. 2011; 39(6):655-666.

43. Xia, C.Y.; Ding, S.; Wang, C.J.; Wang, J.; Chen, Z.Q. Risk analysis and enhancement of cooperation yielded by the individual reputation in the spatial public goods game. IEEE Systems Journal. 2017; 11:1516-1525.

44. Chen, Y.; Ding, S.; Zheng, H.D.; Zhang, Y.T.; Yang, S.L. Exploring diffusion strategies for mHealth promotion using evolutionary game model. Applied Mathematics and Computation 2018; 336:148-161.

45. Li, Q.; Li, M.C.; Lv, L.; Guo, C.; Lu, K. A new prediction model of infectious diseases with vaccination strategies based on evolutionary game theory. Chaos, Solitons and Fractals. 2017; 104:51-60.

46. Antoci, A.; Maccioni, A.F.; Galeotti, M.; Russu,P. Defensive medicine, liability insurance and malpractice litigation in an evolutionary model. Nonlinear Analysis Real World Applications. 2018; 47:414-435.

47. Burke, M.A.; Fournier, G.M.; Prasad, K. Geographic variations in a model of physician treatment choice with social interactions. Journal of Economic Behavior and Organization. 2010; 73:418-432. 
48. Yu, J.N.; Zhang, T.T.; Liu, Z.; Hatab, A.A.; Lan, J. Tripartite data analysis for optimizing telemedicine operations: Evidence from Guizhou province in China. International Journal of Environmental Research and Public Health. 2020; 17:375.

49. Smith, J.M. Evolution and the theory of games: In situations characterized by conflict of interest, the best strategy to adopt depends on what others are doing. American Scientist. 1976; 64: 41-45.

50. Liu, X.X.; Guo, X.T.; Wu, H.; Wu, T.S. The impact of individual and organizational reputation on physicians' appointments online. International Journal of Electronic Commerce. 2016; 20(4):551-577.

Figure Legends

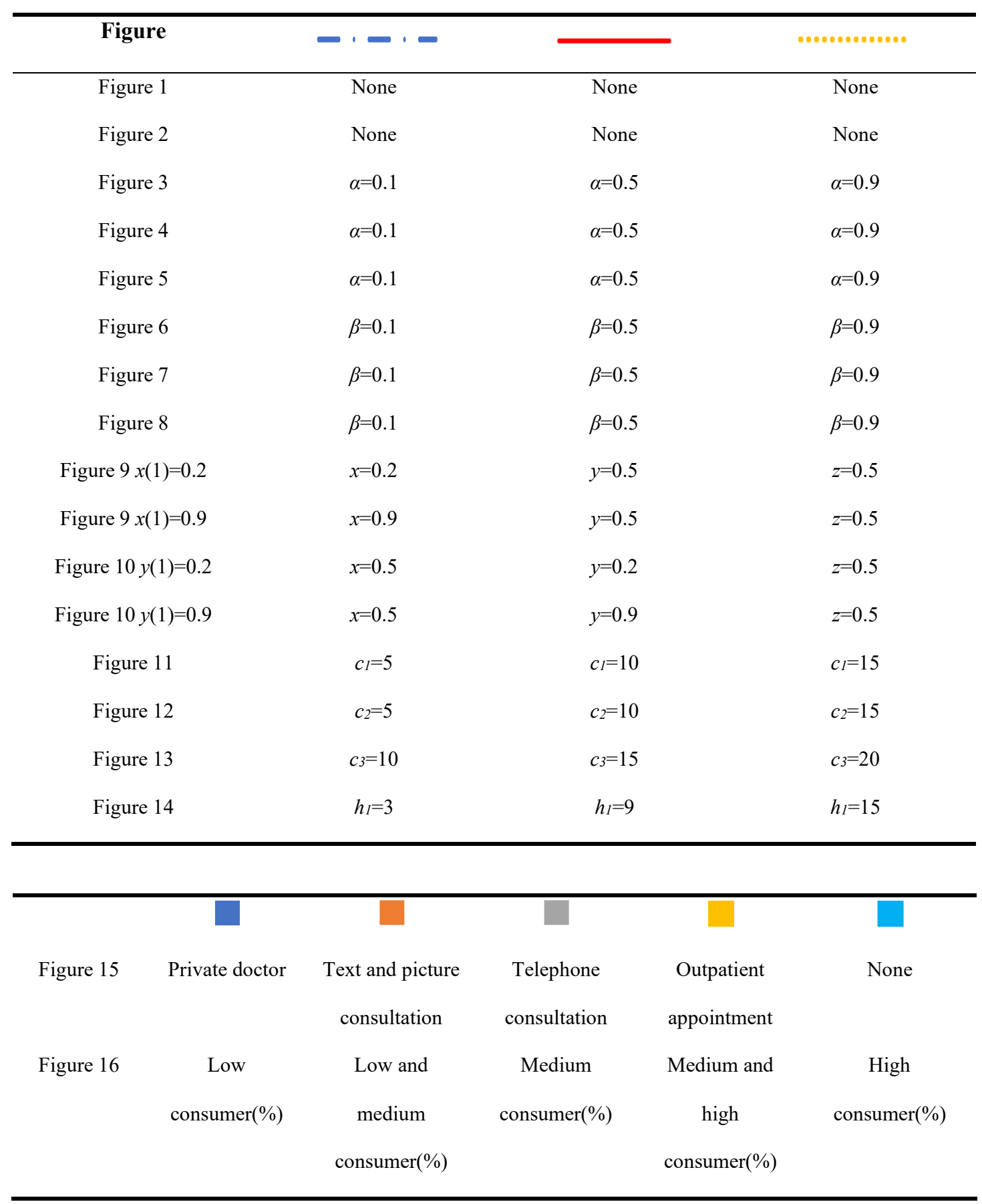


Figure title

\begin{tabular}{|c|c|}
\hline Figure & Title \\
\hline Figure 1 & The research framework of the whole paper \\
\hline Figure 2 & The relationship among the three stakeholders \\
\hline Figure 3 & The evolution path of doctors' strategy under different QISC \\
\hline Figure 4 & The evolution path of patients' strategy under different QISC \\
\hline Figure 5 & The evolution path of platforms' strategy under different QISC \\
\hline Figure 6 & The evolution path of doctors' strategy under different IPISC \\
\hline Figure 7 & The evolution path of patients' strategy under different IPISC \\
\hline Figure 8 & The evolution path of platforms' strategy under different IPISC \\
\hline Figure 9 & The evolution track of three-party strategy selection under different initial states of doctors \\
\hline Figure 10 & The evolution track of three-party strategy selection under different initial states of patients \\
\hline Figure 11 & Evolutionary trajectory of doctor's strategy selection under different registration costs \\
\hline Figure 12 & Evolutionary trajectory of doctors' strategy selection under different time costs \\
\hline Figure 13 & Evolutionary trajectory of doctors' strategy selection under different reputation loss \\
\hline Figure 14 & Evolutionary trajectory of patient's strategy selection under different online healthcare costs \\
\hline Figure 15 & Number of online doctors at all levels \\
\hline Figure 16 & Analysis on the consumption ability of Spring Rain Doctor's users \\
\hline
\end{tabular}




\section{Figures}

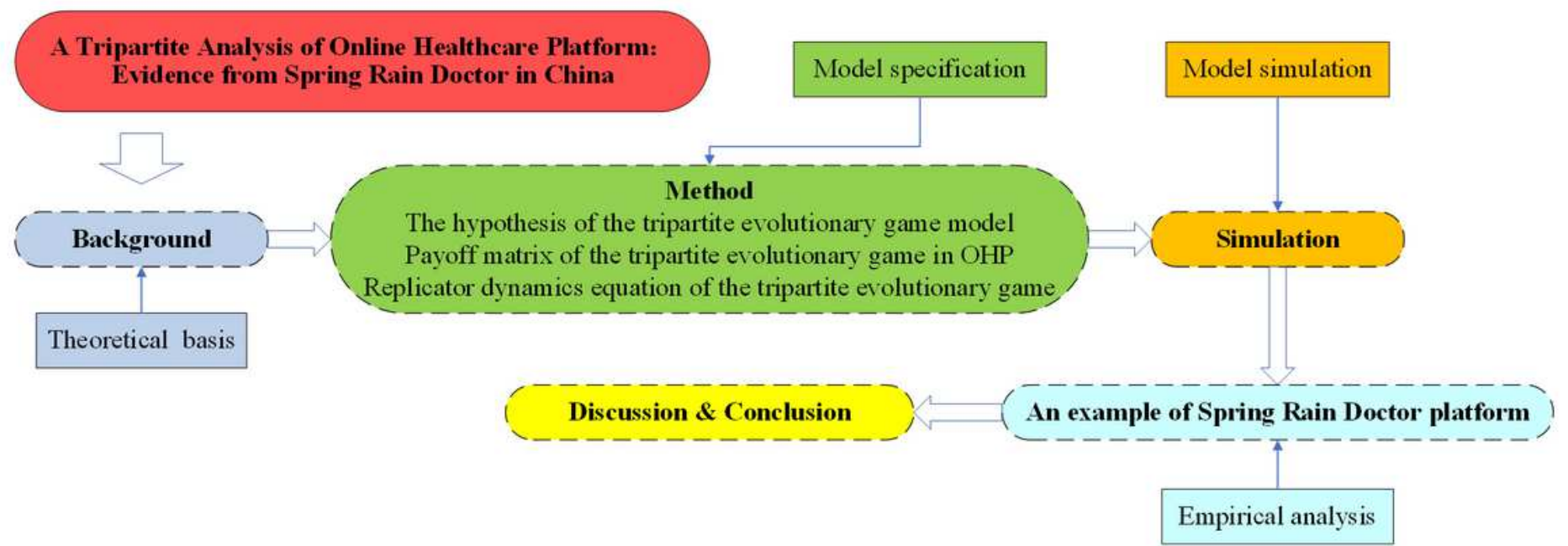

\section{Figure 1}

The research framework of the whole paper

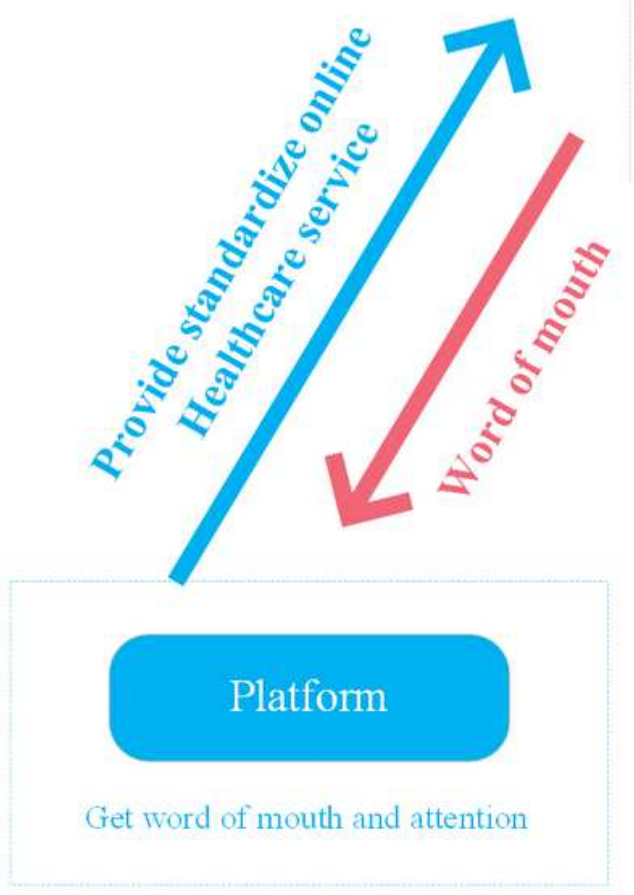

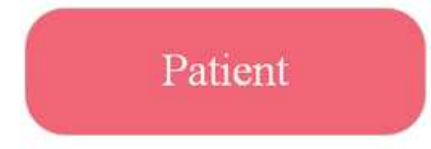

Health management and counseling

\section{Provide a platform} for doctors and patients

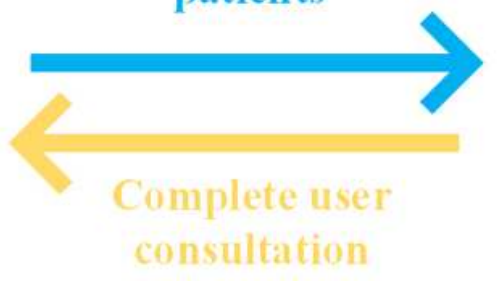

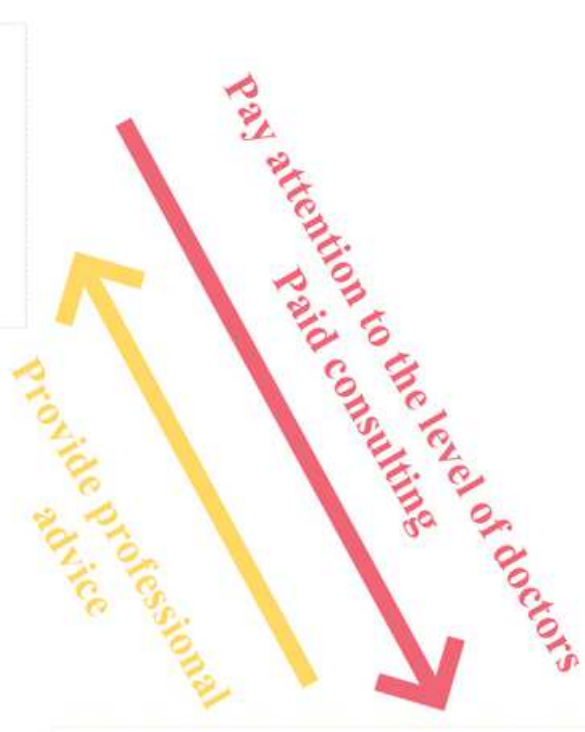

Doctor

\section{Figure 2}

The relationship among the three stakeholders 


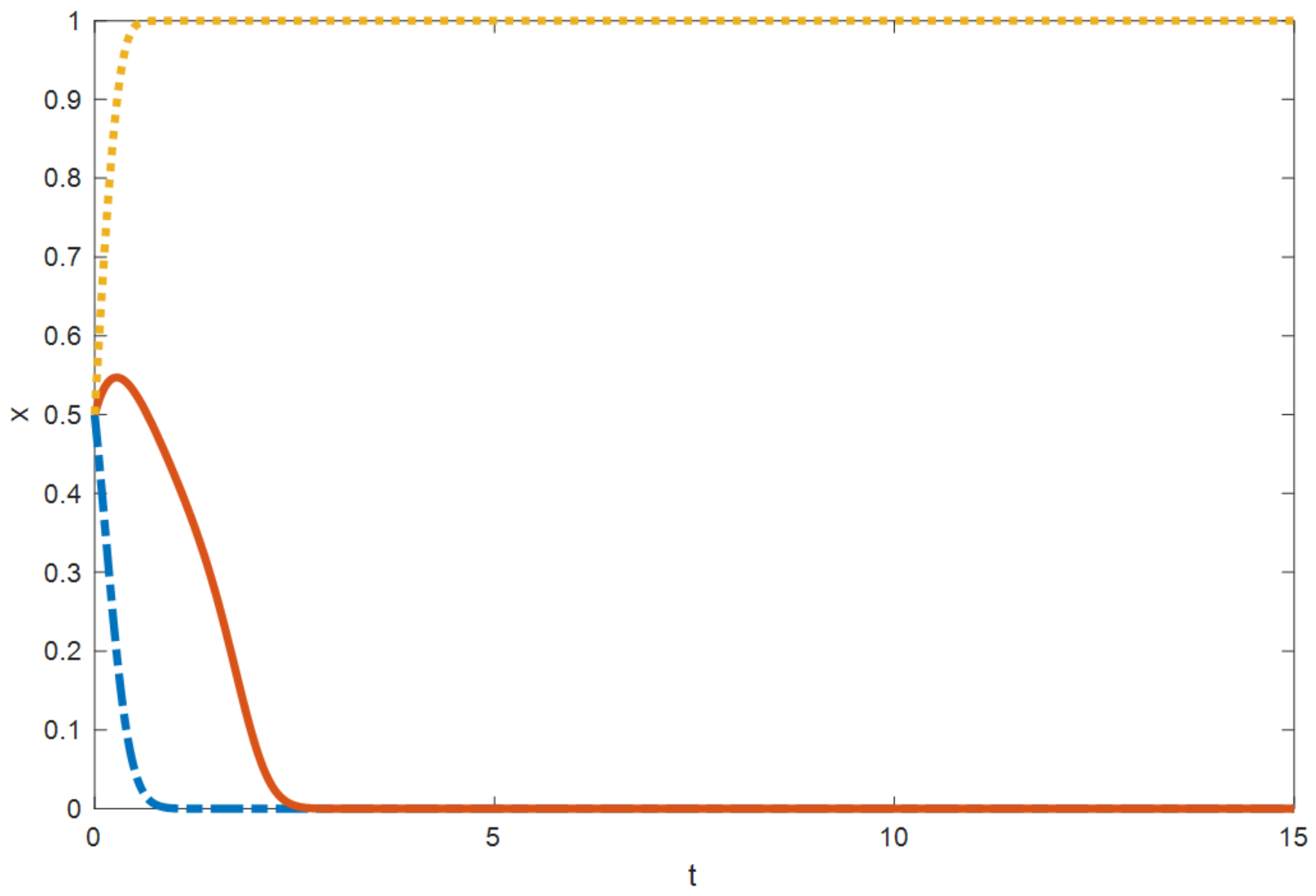

Figure 3

The evolution path of doctors' strategy under different QISC 


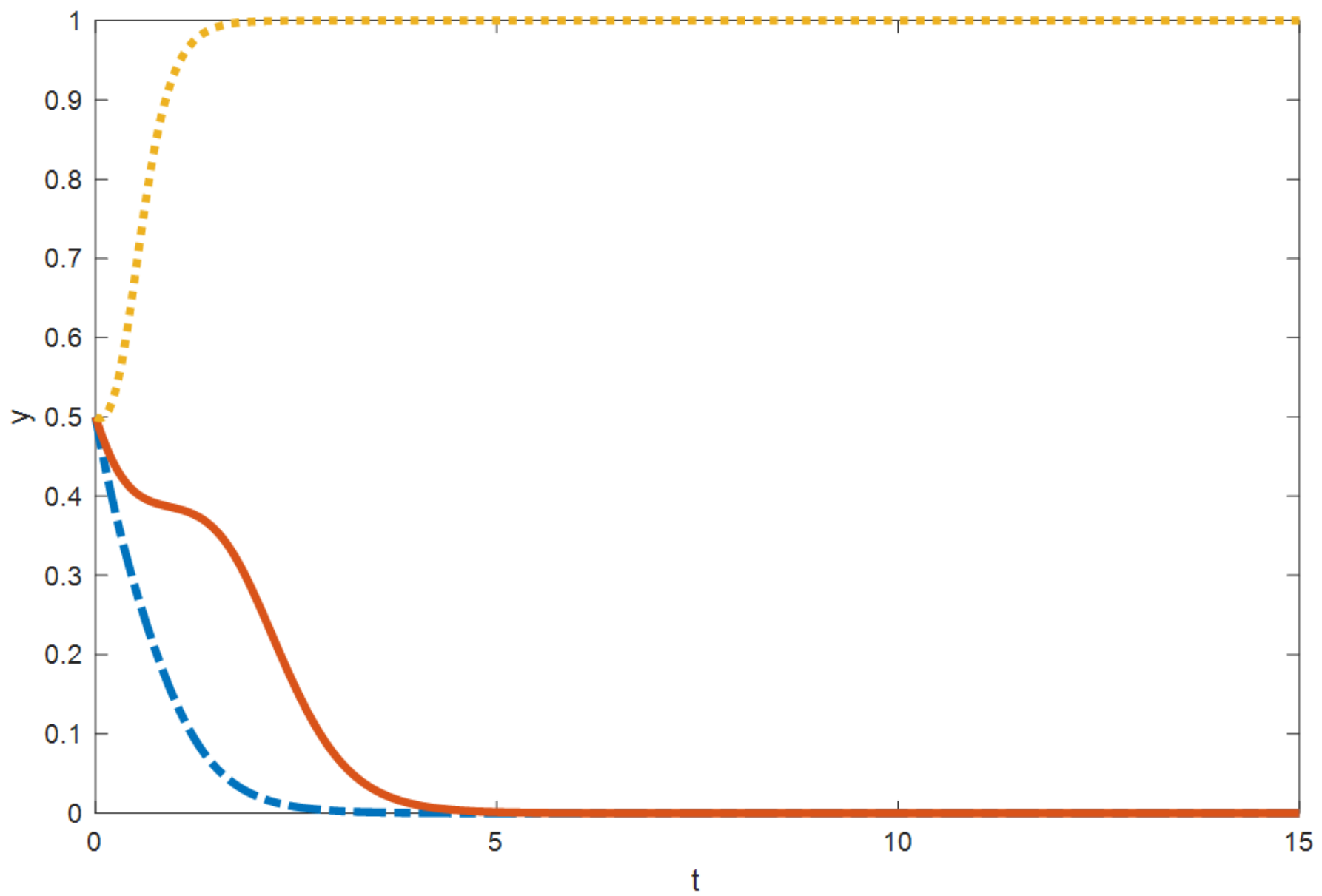

Figure 4

The evolution path of patients' strategy under different QISC 


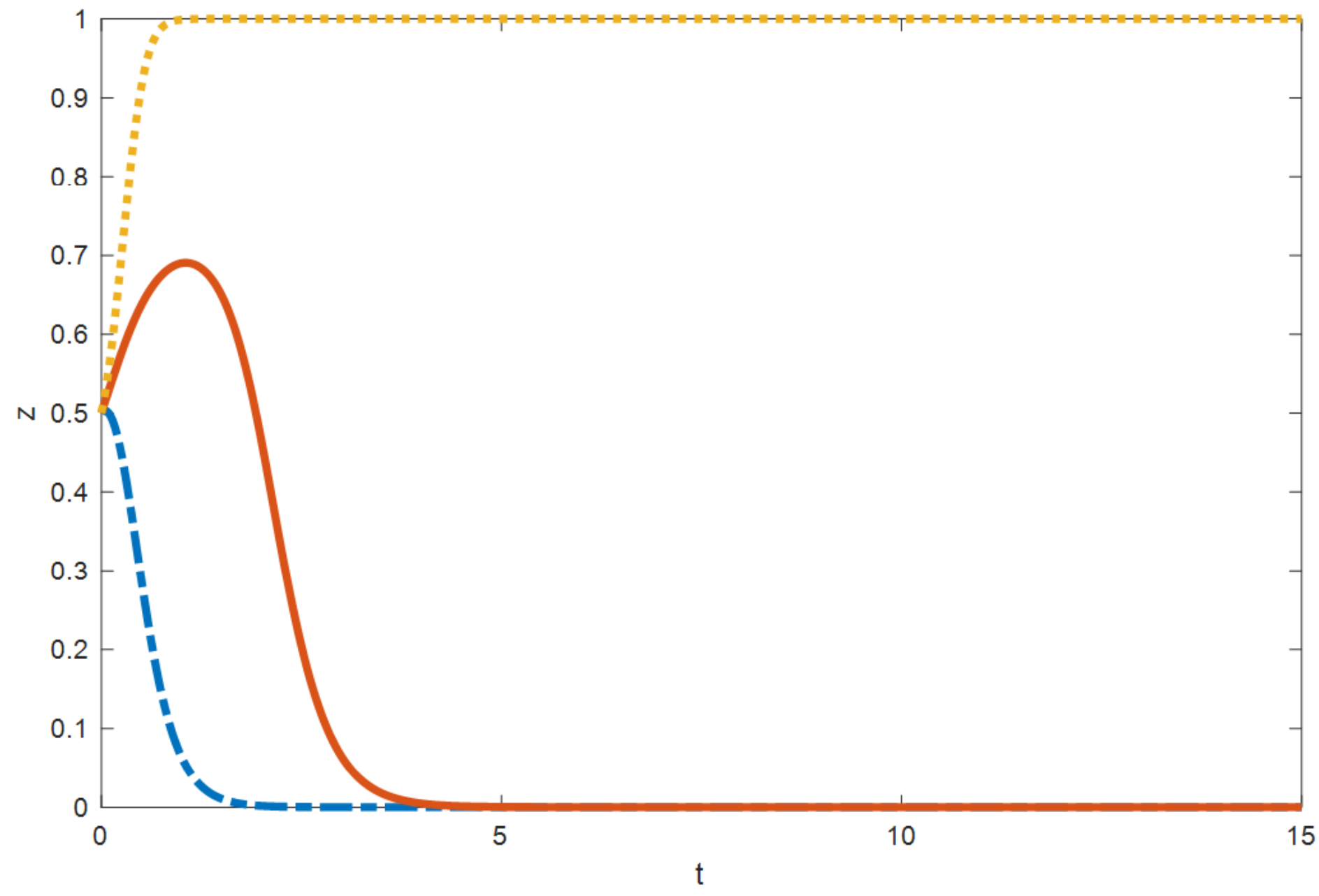

Figure 5

The evolution path of platforms' strategy under different QISC 


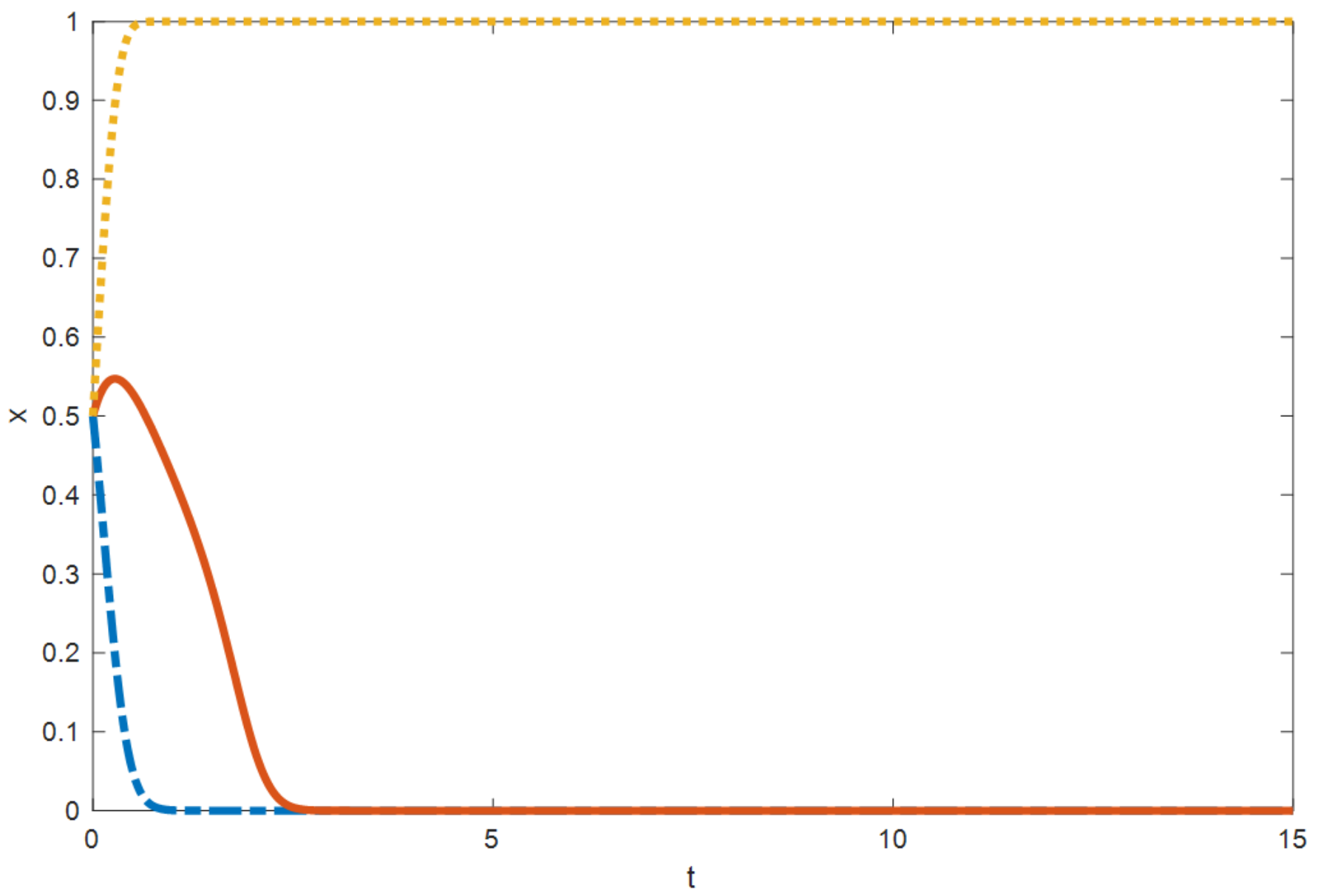

Figure 6

The evolution path of doctors' strategy under different IPISC 


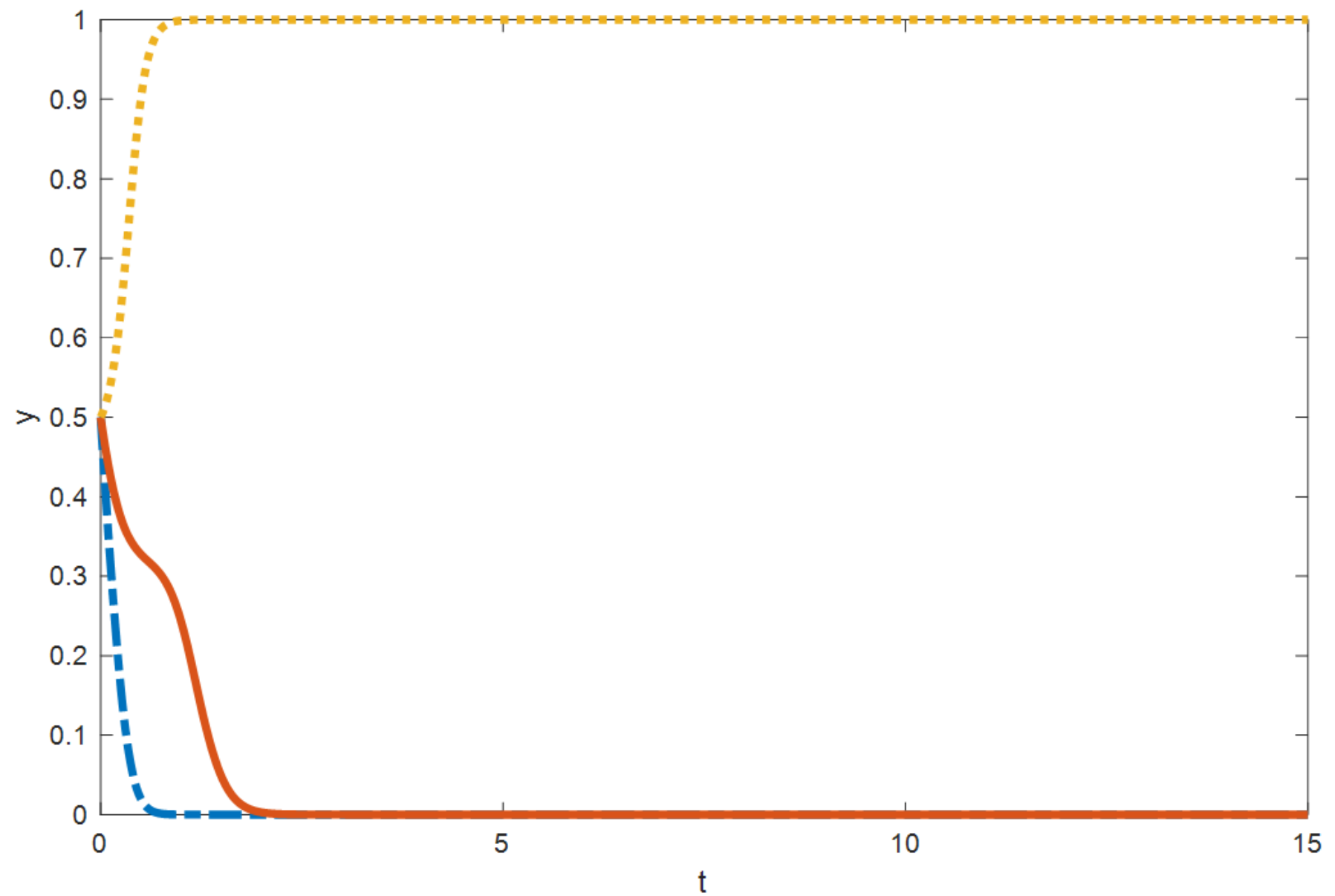

Figure 7

The evolution path of patients' strategy under different IPISC 


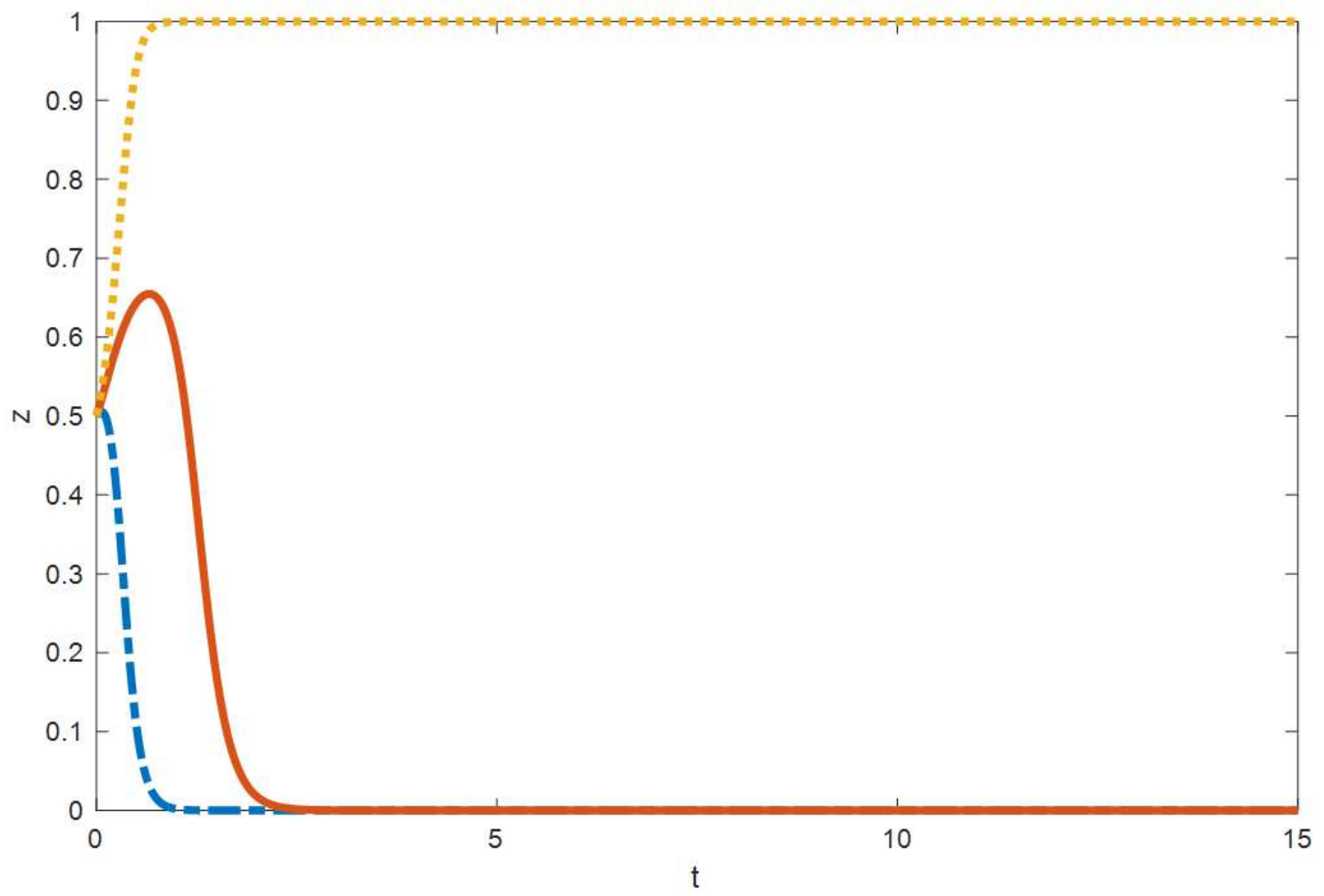

Figure 8

The evolution path of platforms' strategy under different IPISC
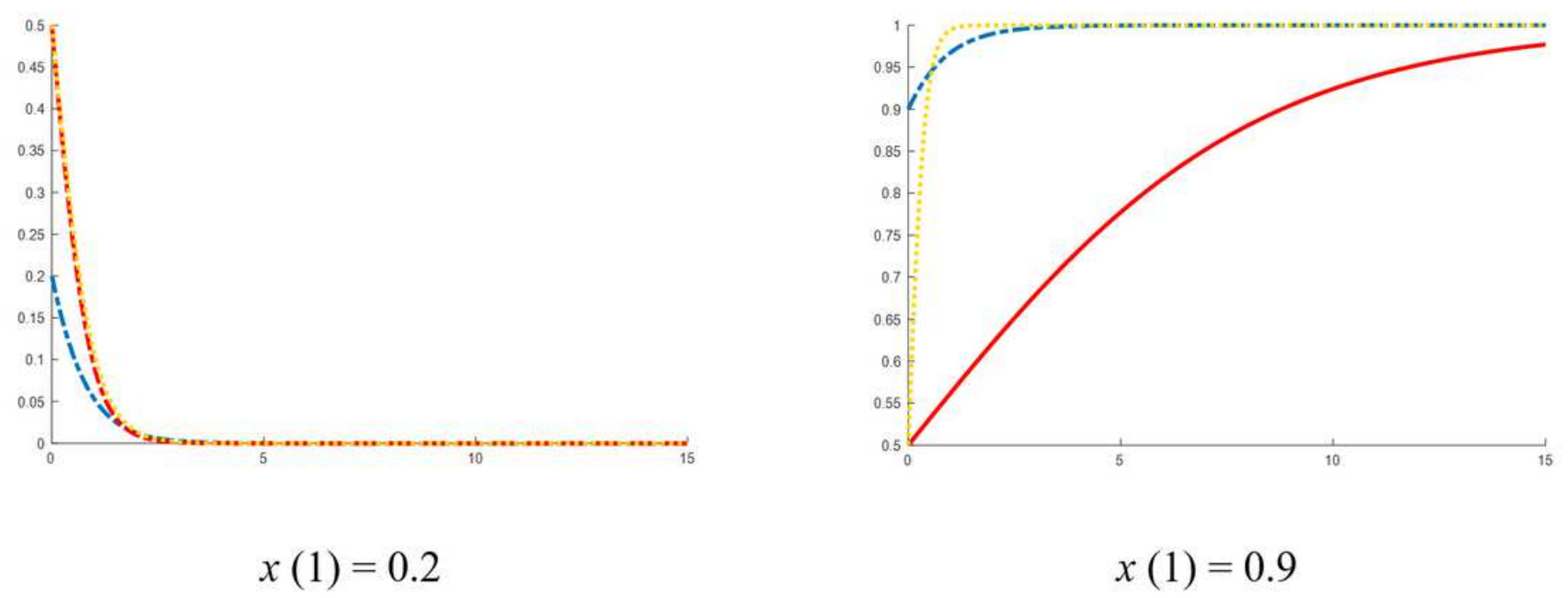

Figure 9

The evolution track of three-party strategy selection under different initial states of doctors 


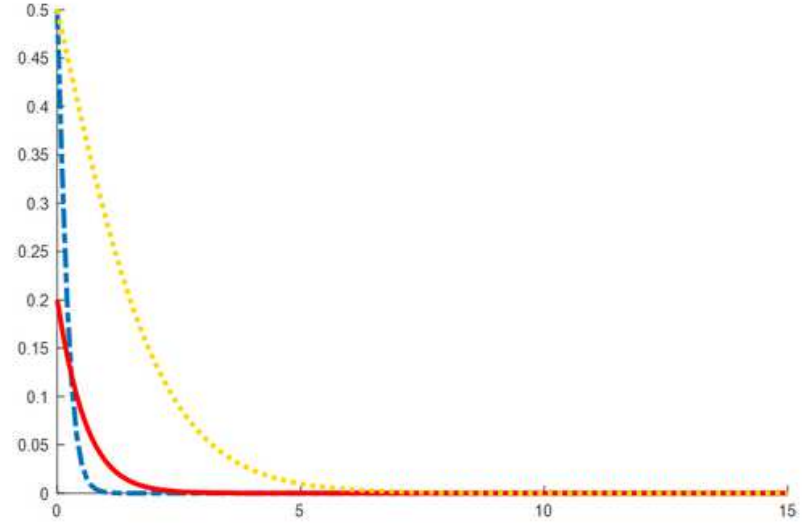

$y(1)=0.2$

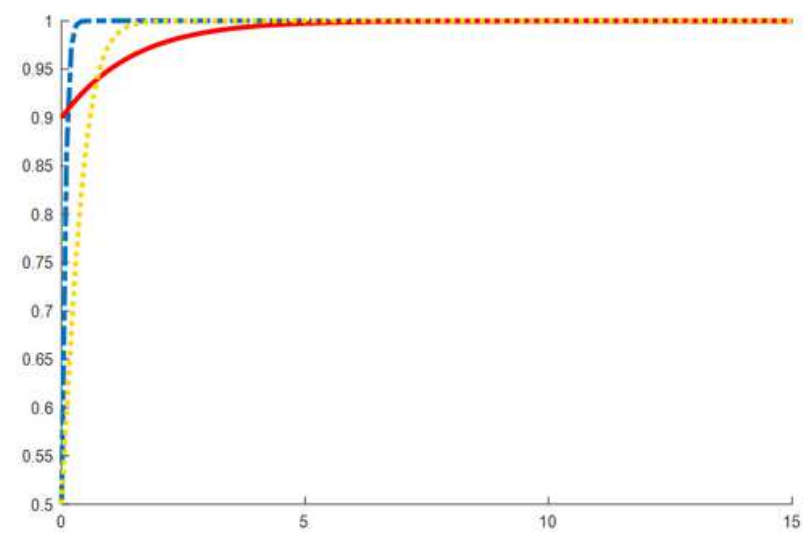

$y(1)=0.9$

Figure 10

The evolution track of three-party strategy selection under different initial states of patients

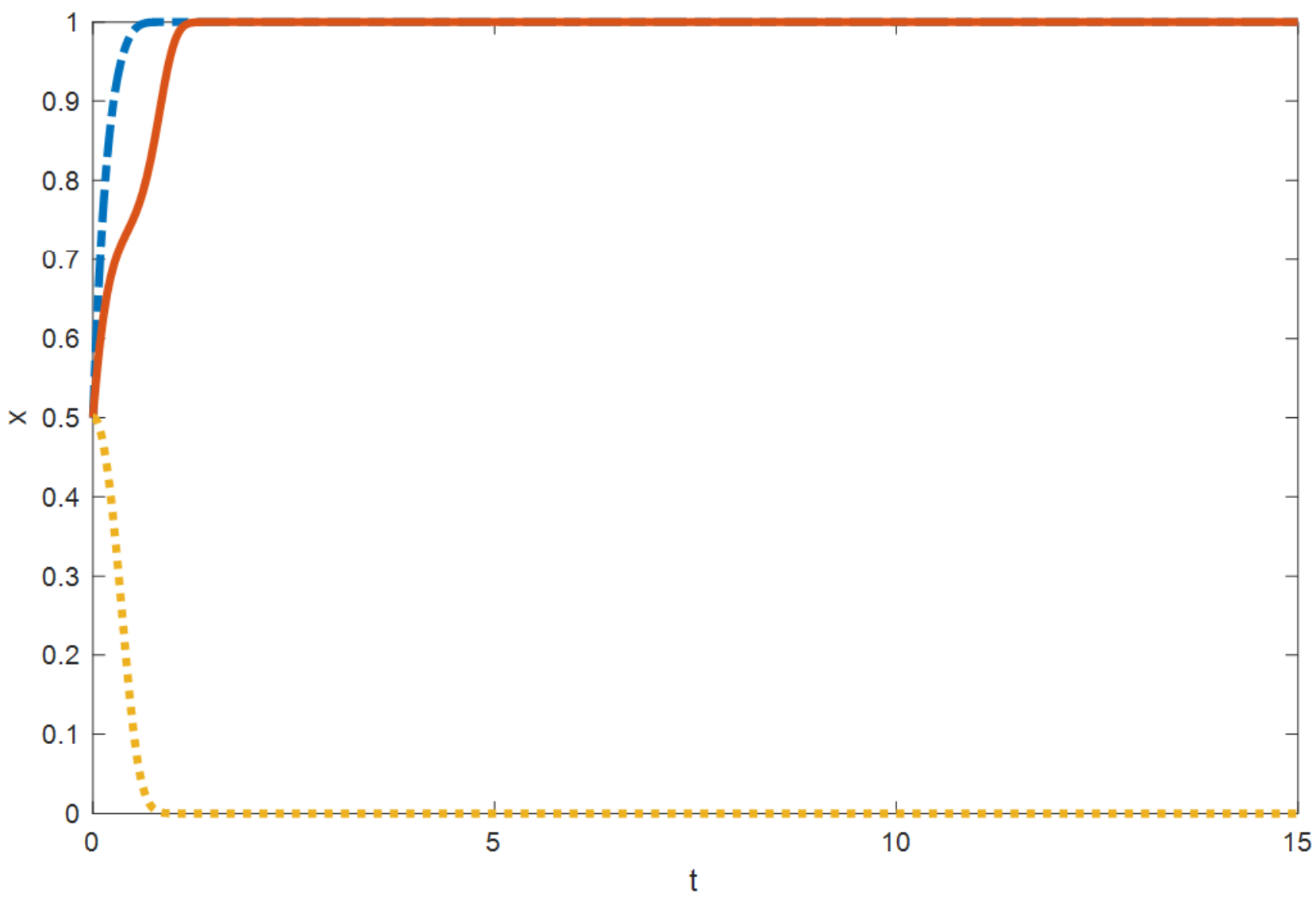

Figure 11

Evolutionary trajectory of doctor's strategy selection under different registration costs 


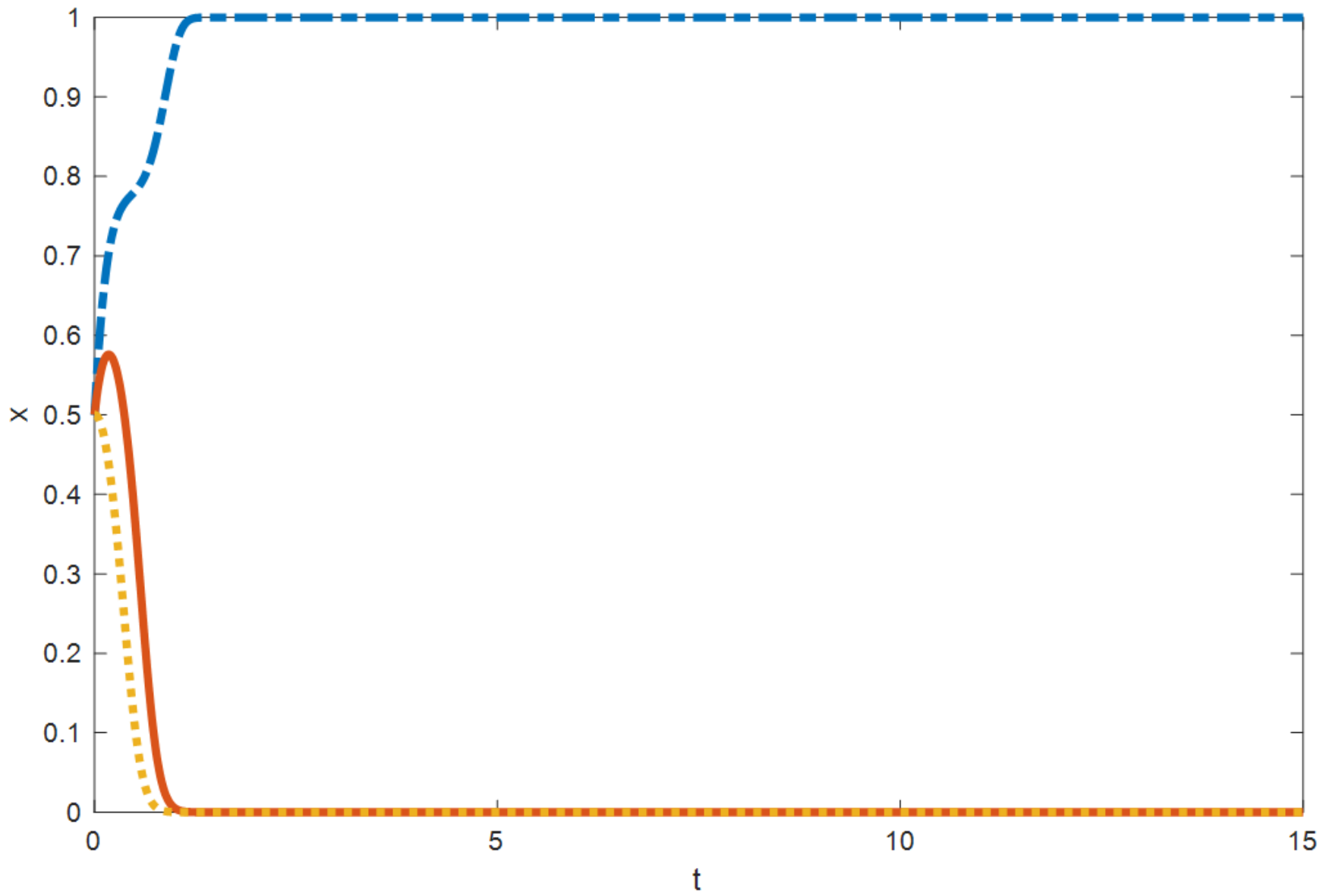

Figure 12

Evolutionary trajectory of doctors' strategy selection under different time costs 


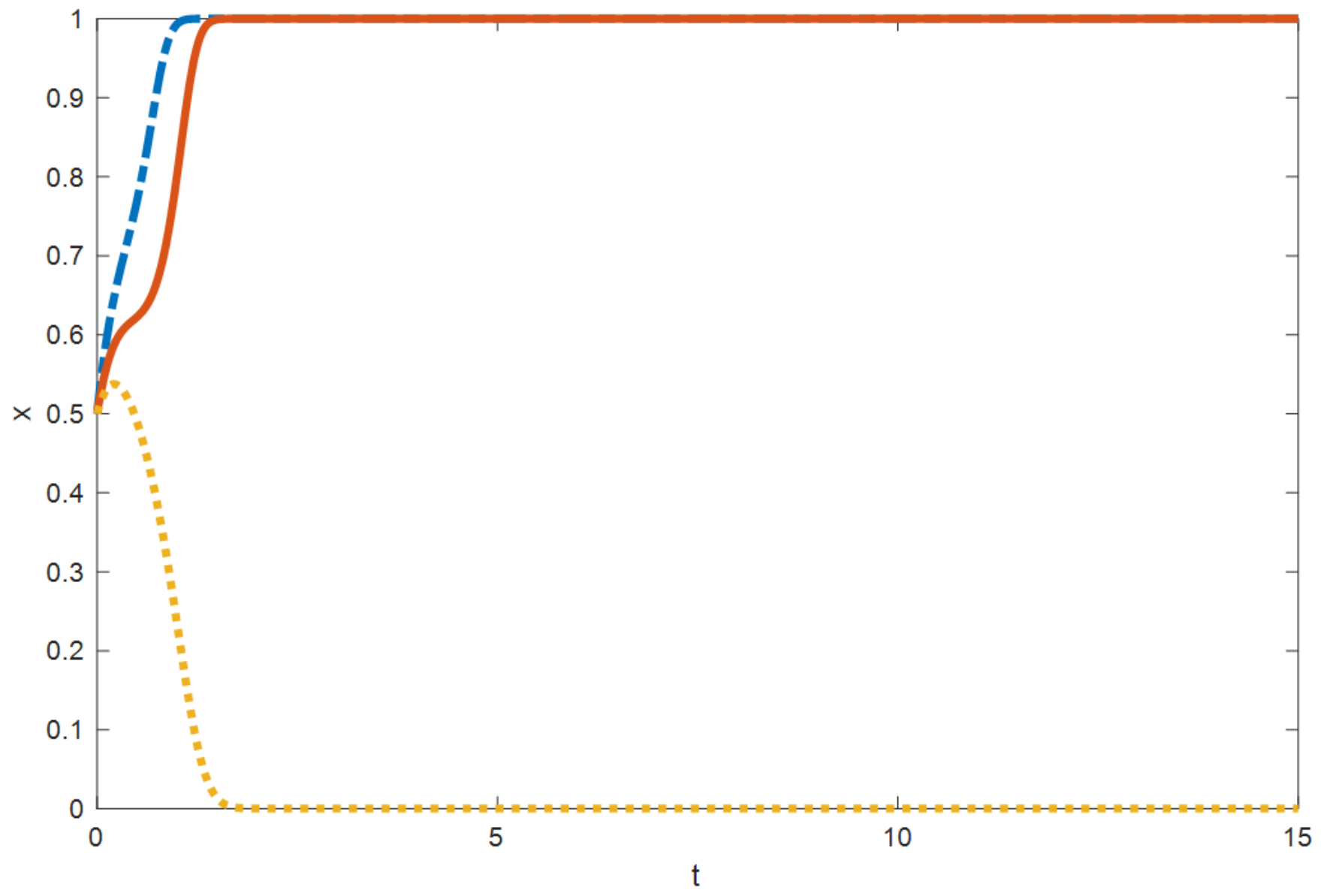

Figure 13

Evolutionary trajectory of doctors' strategy selection under different reputation loss 


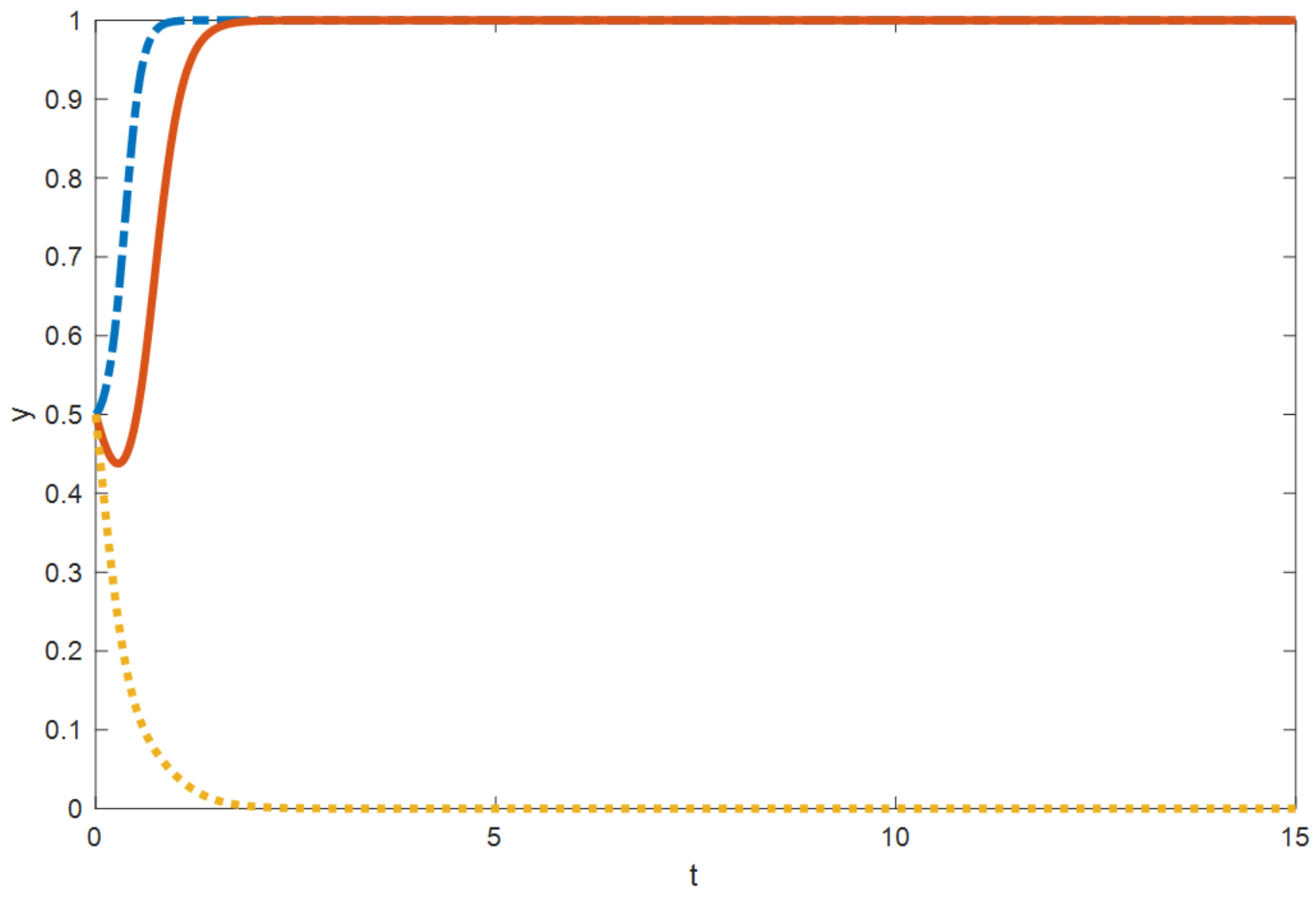

Figure 14

Evolutionary trajectory of patient's strategy selection under different online healthcare costs 


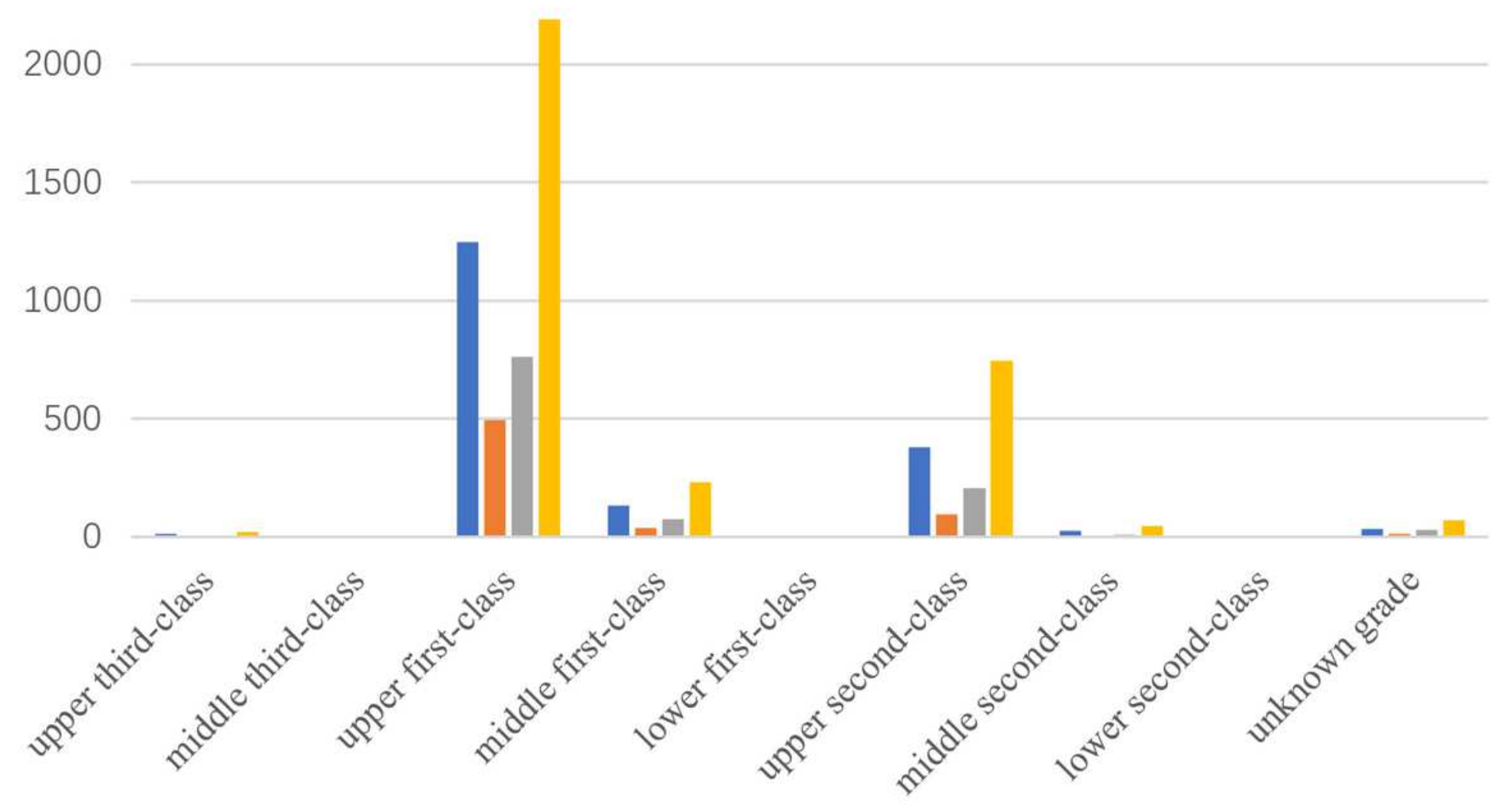

Figure 15

Number of online doctors at all levels 


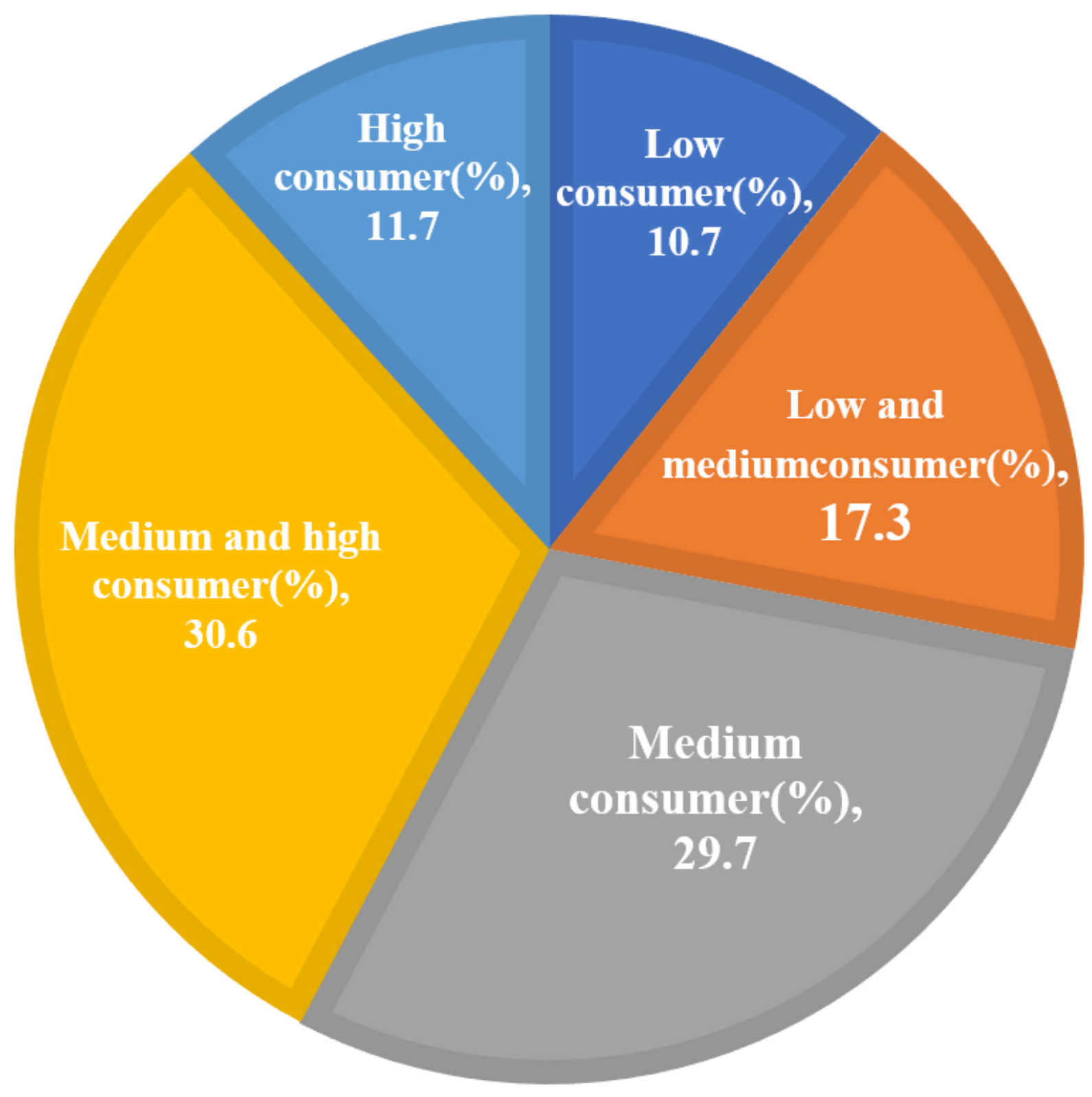

Figure 16

Analysis on the consumption ability of Spring Rain Doctor's users 